\title{
Drug discovery and computational strategies in the multitarget drugs era
}

\author{
Jéssika de Oliveira Vianaํㅜ, Mayara Barbalho Félix ${ }^{1}$, Mayara dos Santos Maia ${ }^{1}$, \\ Vanessa de Lima Serafim ${ }^{1}$, Luciana Scotti ${ }^{1}$, Marcus Tullius Scotti ${ }^{1 *}$ \\ ${ }^{1}$ Program of Natural and Synthetic Bioactive Products (PgPNSB), Health Sciences Center, Federal University of Paraiba, \\ João Pessoa-PB, Brazil
}

\begin{abstract}
The pharmaceutical industry is increasingly joining chemoinformatics in the search for the development of new drugs to be used in the treatment of diseases. These computational studies have the advantage of being less expensive and optimize the study time, and thus the interest in this area is increasing. Among the techniques used is the development of multitarget directed ligands (MTDLs), which has become an ascending technique, mainly due to the improvement in the quality of treatment involving several drugs. Multitarget therapy is more effective than traditional drug therapy that emphasizes maximum selectivity for a single target. In this review a multitarget drug survey was carried out as a promising strategy in several important diseases: neglected diseases, neurodegenerative diseases, AIDS, and cancer. In addition, we discuss Computer-Aided Drug Design (CADD) techniques as a tool in the projection of multitarget compounds against these diseases.
\end{abstract}

Keywords: Drug design. Multitarget compounds. In silico. Diseases.

\section{INTRODUCTION}

According to the definition of Richard Morphy, the multitarget drugs are defined as compounds that are designed to modulate multiple targets of relevance to a disease, with the overall goal of enhancing efficacy and/ or improving safety (Morphy, Rankovic, 2005).

The multitarget drug is a key that can open multiple locks. Research into a multifunctional compound can follow two paths: comprehensive experimental analyses, or by first using computer aided rational drug design; followed by screening and identifying potential targets, optimizing the research, and avoiding higher expenses (Yildirim et al., 2007; Lavecchia, Giovanni, 2013). Furthermore, multitarget therapy is more effective than traditional drug therapy, which emphasizes maximum selectivity for a single target. By interacting with different targets, complex diseases of multifactorial origin are treated with greater effectiveness and in less time. Requiring smaller doses for simultaneous targets,

\footnotetext{
*Correspondence: M. T. Scotti. Pós-graduação em Produtos Naturais e Sintéticos Bioativos, Centro de Ciências da Saúde, Universidade Federal da Paraíba, João Pessoa-PB, Brazil. E-mail: mtscotti@gmail.com
}

multitarget therapies also feature lower toxicity and reduced side effects (Morphy, Rankovic, 2005).

However, despite the therapeutic potential of multitarget compounds, there are challenges regarding their discovery and development. Like the difficulty in choosing the right combination of targets involved in the diseases of interest, necessitating the understanding of target-disease action mechanism relationships and adverse effects profile, as well as establishing similar levels of action intensity for each target and design the molecules to avoid interactions with unwanted targets. In addition, it should be noted that only one part of the molecule can interact with each of the proposed targets, and the other part may become an obstacle to the binding event, reducing binding action due to enteric and entropybased approaches. In this way, to include some degree of flexibility in the molecule can help the pharmacological characteristics, however, taking care that there is not an excess of flexibility, thus interfering negatively in the binding affinity (due to the unfavorable entropic loss associated with the binding event) or the bioavailability of the drug (Jayaraman et al., 2013), being these critical factors to be reflected in the planning of these compounds (Decker, 2007; Ramsay et al., 2018). 
The term "one-target-one-disease" has been growing during the discovery of new drugs in recent years, mainly due to the complexity of some diseases (Bawa et al., 2016). Among these drugs, another term is "cocktail therapy," which is based on the combination of several drugs in clinical practice, in which these various drugs can act on several targets and may have synergistic effects in treatment. However, these effects may be hindered by disadvantages, which involve the pharmacokinetics of these compounds, the various side effects that each drug can cause, and the possible interactions between the drugs administered (Lin et al., 2017; Li et al., 2016).

Due to problems encountered in the use of these techniques, a new approach has emerged called multitarget-directed ligands (MTDLs) that is being used as a way to overcome undesirable clinical effects. As a goal, this technique is based on the principle "one-compoundmultiple-targets," that is, the use of a compound that can interact with more than one target, guaranteeing greater effectiveness and fewer side effects (Morphy, 2012).

Using computer-aided drug design (CADD), in silico methods were developed to facilitate the screening of new compounds with multitarget characteristics. Several studies have been reported in the literature addressing these methods targeting multiple targets (Ma et al., 2010). Lately, many such techniques are key tools in multi-target drug discovery (MTDD) to find drug leads that at the same time interact with multiple target agents. These techniques are categorized into fragment-based and combinatorial approaches. Conventionally, for each individual target and to find virtual hits, combinatorial approaches perform parallel searches to determine which hit interacts with more than one target. Because of such inquires, novel drugs for targets to use for one disease and/or to decrease the resistance, have been found (Abdolmaleki, Ghasemi, Ghasemi, 2017).

Design and development of a single chemical entity that acts simultaneously at multiple molecular targets is gaining major consideration in drug discovery. On the other hand, several multi-target molecular entities are currently emerging from the drug discovery programs, and some of these agents are now in clinical use for the management of various hematologic malignancies and solid tumors (Gentile et al., 2017).

Most different FDA approved multikinase inhibitors for use of cancer therapy as Vandetanib (a), Regorafenib (b), Ponatinib (c), Crizotinib (d) Cabozantinib (e) in Figure 1 cited in review of Gentile et al. (2017).

Some others examples as Lapatinib (Tykerb) Figure 2 (a) is a reversible, ATP-competitive inhibitor of the HER2 and EGFR tyrosine kinases (Konecny et al.,
2006), and Duvelisib (Figure 2 (b)), a novel oral dual inhibitor of PI3K- $\delta, \gamma$, is clinically active in advanced hematologic malignancies (Flinn et al., 2018).

This review discusses studies that used in silico tools to discover new compounds that have potential multitarget activity for several diseases, among neglected diseases, neurodegenerative diseases, and different types of cancer.

\section{NEGLECTED DISEASES (ND)}

Neglected Tropical Diseases (NTDs) is a diverse group of communicable diseases that prevail in tropical and subtropical conditions in 149 countries (WHO, 2018d). NDs are generally associated with poverty, induced by inequalities and neglect by governments in a way that generates disinterest in the pharmaceutical industry. They reach the lives of one billion people worldwide and threaten the health of millions of people (WHO, 2010), causing 170,000 deaths a year (Watts, 2017). They are diseases caused by infectious agents such as viruses, bacteria, protozoa and helminths, prevalent in developing and underdeveloped countries (de Souza, 2010). They entail profound financial costs to the population, such as visceral leishmaniasis, whose costs exceed $20 \%$ of total annual household expenditures for $30 \%$ of households in Ethiopia, about a quarter of households in Bangladesh and Sudan, and 14\% of households in India (Watts, 2017).

There is a difficulty in investing in research for this type of disease, which makes it increasingly difficult to combat and prevent it. Therefore, it is necessary to study the therapy of neglected diseases, and the computational studies are becoming more and more associated in this field, due to their low cost and the flexibility of the techniques used. Chemoinformatics plays a very important role in the discovery of new multitarget agents, which may be more effective and have low toxicity, to assist in the treatment of these diseases.

\section{LEISHMANIASIS}

A disease caused by parasites of the genus Leishmania, which infects about 15 million people around the world (Loriá-Cervera, Andrade-Narváez, 2014; Reithinger et al., 2007), with 200.000-400.000 new cases of visceral leishmaniasis annually (DNDi, 2018b), as well as $90 \%$ of the cases of mucocutaneous leishmaniasis occurring in Bolivia, Brazil and Peru (WHO, 2018c). For treatment, the antimonial pentavelente is still used as the medicine of first choice, or the amphotericina B and pentamidine like drugs as a second choice. These are toxic, for some we still do not know the mechanism of action 
<smiles>COc1cc2c(Nc3ccc(Br)cc3F)ncnc2cc1OCC1CCN(C)CC1</smiles>

(a)

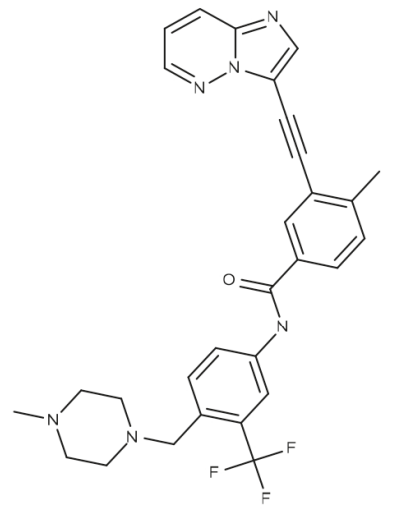

(c)

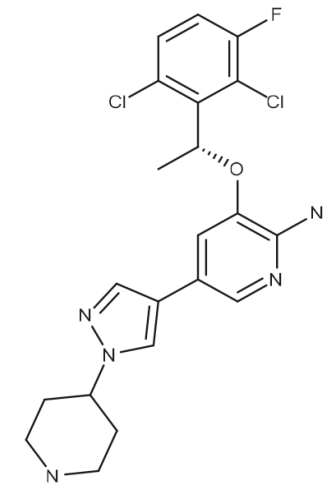

(d)<smiles>CNC(=O)c1cc(Oc2ccc(NC(=O)Nc3ccc(O)c(C(F)(F)F)c3)c(F)c2)ccn1</smiles>

(b)<smiles>COc1cc2nccc(Oc3ccc(NC(=O)C4(C(=O)Nc5ccc(F)cc5)CC4)cc3)c2cc1OC</smiles>

(e)

FIGURE 1 - Vandetanib (a), Regorafenib (b), Ponatinib (c), Crizotinib (d) Cabozantinib (e).<smiles>CS(=O)(=O)CCNCc1ccc(-c2ccc3ncnc(Nc4ccc(OCc5cccc(F)c5)c(Cl)c4)c3c2)o1</smiles>

(a)<smiles>CC(Nc1ncnc2[nH]cnc12)c1cc2cccc(Cl)c2c(=O)n1-c1ccccc1</smiles>

(b)

FIGURE 2 - Lapatinib (a), Duvelisib (b).

involved, besides the fact that some species are already resistant (Arboleda et al., 2013; Sundar et al., 2002). Therefore, there is a need for research investigating new compounds that are effective in the therapy of this disease by acting on more than one target in the parasite and that is not toxic to the patient.

Studies by Trossini, Maltarollo and Schmidt (2014), evaluated by Hologram QSAR models (HQSAR) multitargets compounds. From the series of 40 active sesquiterpene lactones against some species of parasites, including Leishmania donovani, PLS models generated using different latent variables were evaluated through cross-validation (exit-one-out and leave-n-out) and validation external. Of the five best HQSAR models, the highest value of $\mathrm{Q}^{2} \mathrm{LOO}$ was 0.78 and $\mathrm{R}^{2}$ ext of 0.944 , being the coefficients for $L$. donovani (Table I).

Another study, by Bernal, Coy-Barrera (2014), used a set of 123 sesquiterpenes with leishmanicidal 
TABLE I - Model data generated from Leishmania donovani

\begin{tabular}{cc}
\hline & HQSAR Models \\
\cline { 2 - 2 } & Ldon \\
\hline$F_{\text {dist }}$ & $\mathrm{A} / \mathrm{C} / \mathrm{Ch} / \mathrm{DA}$ \\
$F_{\text {size }}$ & $4-7$ atoms \\
$H L$ & 83 \\
$P C$ & 5 \\
$N$ & 25 \\
$q^{2}{ }_{\text {LOO }}$ & 0.775 \\
$S E V$ & 0.279 \\
$q^{2}{ }_{C V}$ & $0.753 \pm 0.02$ \\
$r^{2}$ & 0.972 \\
$S E E$ & 0.098 \\
$r_{\text {test }}^{2}$ & 0.944 \\
\hline
\end{tabular}

Fdist: fragment distinction; Fsize: fragment size; HL: hologram length; PC: number of PLS principal components; $\mathrm{N}$ : number of compounds of training set; SEV: standard error of validation; SEE: standard error of estimation.

activity, which was subdivided into sesquiterpenecoumarins, agarofurans, drimanes, pseudoguaianolides, germacranolides, guaianolides, eudesmanolides, and xanthanolides. Molecular docking was then performed in order to verify some multitarget compound. Four target enzymes of two species of Leishmania were used: pteridine reductase (PTR1, PDB: 2QHX), cysteine synthase (LmCS, PDB: 4AIR), trypanosintetase (TryS, PDB: 2VOB) from L. major and N-myristoyl transferase (NMT, PDB: 2WUU) from $L$. donovani for a better understanding of the mode of binding of these compounds.

Thus, it was possible to verify that two sesquiterpene coumarins (Figure 3) bind more easily to PTR1 and TryS, and some xanthanolides (Figure 4) also showed higher affinity for PTR1 and LmCS binding, for inhibition purposes. These results are promising for structural optimization studies aiming at a better activity.

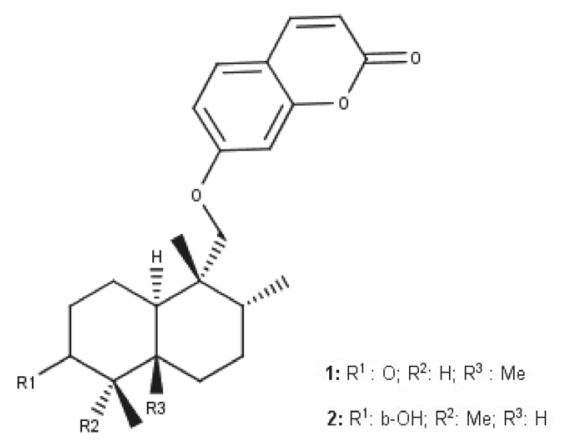

FIGURE 3 - Sesquiterpene coumarins.
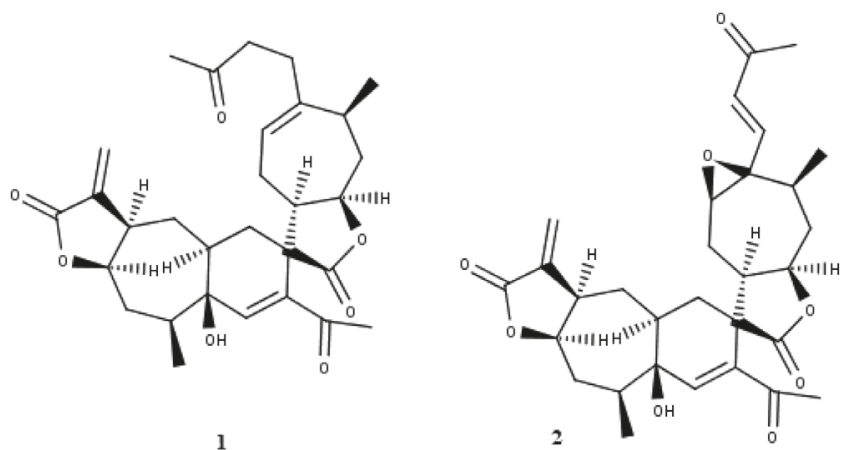

FIGURE 4 - Xanthanolide sesquiterpenes.

Among other classes of natural products, a study was conducted by Lorenzo et al. (2016) with alkaloids, where the potential activity of azaphenanthrene alkaloids eupolaramine, imbiline 1, imbiline 4, sampangine, 3-methoxyisampangine, and 4-methoxyampampine of $A$. dolichocarpa, as well as a database with 142 aporphinal alkaloids isolated from Annonaceae, using virtual screening (VS) through the search of active molecules against Leishmania donovani. These were classified according to $\mathrm{pIC}_{50}$ values to develop and validate a model using the Random Forest algorithm. Using Volsurf + program v. 1.0.7, 128 molecular descriptors were generated, which served as input data in the Knime program (see 2.10.0), for the consequent generation of the model.

In addition, based on reports from the literature on a multitarget model of computational chemistry to predict the results of experimental tests for Leishmania (García et al., 2011), the molecular docking study was carried out using five enzymes different from $L$. donovani extracted from the PDB. From this analysis, it was suggested that aporphynic alkaloid (xyloguyelline) (Figure 5) be analyzed as a molecule with potential multitarget for the treatment of leishmaniasis, presenting activity against five strategic enzymes for treatment with a probability of activity of $60 \%$.<smiles>COc1c(O)c(OC)c2c3c1CCN[C@@H]3Cc1cc3c(cc1-2)OCO3</smiles>

FIGURE 5 - Xyloguyelline.

\section{Chagas disease: Trypanossoma cruzi}

Also known as American trypanosomiasis, caused by the protozoan Trypanosoma cruzi. The main vector 
involved in the transmission of the parasite to humans is a triatomine bug, also known as a 'kissing bug', and can be transmitted through blood transfusion, transplantation of organs, as well as congenital and oral transmissions. About 6-8 million people are infected and approximately 12,000 deaths occur each year. Less than $1 \%$ of infected persons have access to current diagnosis and treatment, with emergency treatment being indicated for anyone during the acute phase and for those in whom the infection has been reactivated (immunosuppression), in which case the probability of success in the treatment is almost $100 \%$. The drugs used for treatment are benznidazole (first-line treatment in most countries) and nifurtimox (WHO, 2018a; DNDi, 2018a).

One of the enzymes validated in the study of promising targets for the treatment of Chagas disease is the triosephosphate isomerase (TIM), of which its existing inhibitors have low interactions. For this reason, Aguilera et al. (2016) reported the study of derivatives diarylideneketones (Figure 6) in antitrypanosomal activity, with in vitro and $\mathrm{IC}_{50}$ in the range of $86 \mathrm{nM}$, without having negative effects on the mammalian enzyme. In addition to this activity, inhibition of $31 \%$ for the cruzain enzyme was also reported. Molecular docking studies were also performed with the compounds, from which it was possible to predict the target interactions with the study compounds, characterizing the diarylideneketones as a new class of compounds with a dual-target effect.

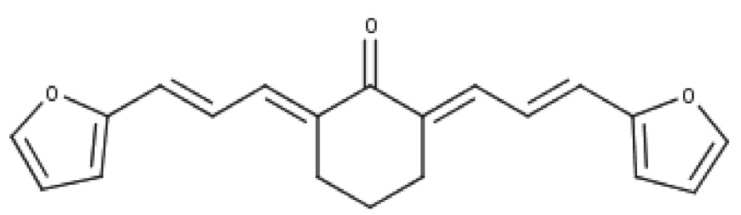

FIGURE 6 - Derivate diarylideneketone that acts on the enzymes TIM/cruzipain in antitrypanosomal activity.

New studies aiming at the antitrypanosomal activity of hybrid derivatives quinone-coumarin (Figure 7) were performed by Belluti et al. (2014). In their study, they showed inhibition of the enzymes glyceraldehyde-3phosphate dehydrogenase (GAPDH) and trypanothione reductase (TR), with $\mathrm{IC}_{50}$ of $5.4 \mu \mathrm{M}$ and $2.32 \mu \mathrm{M}$, respectively. In addition to low cytotoxicity values and non-interference with glutathione reductase of humans, the study analyzed the interactions between the compounds with the targets through docking, confirming the key residue of Cys 166 to GAPDH and Leu399 to TR as essential for the activity.

In studies of Pieretti et al. (2013) they used derivatives of naphthoquinone (Figure 8) in screening<smiles>CN(C)CCOc1ccc2oc(=O)c(-c3ccc(OC4=CC(=O)c5cc6ccccc6cc5C4=O)cc3)cc2c1</smiles>

FIGURE 7 - The hybrid derivative quinone-coumarin that targets the enzymes GAPDH and TR.

for new anti-trypanosomatids, of which an ED50 of 80 $\mathrm{nM}$ was found. In their docking studies they showed that the most active compound, B6, fits the active site of the enzyme TbGAPDH, besides presenting the residue Cys166 as a key point for the activity. Another target was reported by Portela et al. (1996), of which reported the inhibition of derivatives naphthoquinones in inducing oxidative damage in trypanosomatids.<smiles>O=C1C=C(Oc2ccccc2)C(=O)c2ccccc21</smiles>

FIGURE 8 - Derivative naphthoquinone that promotes the activity of anti-trypanosomatids.

\section{Dengue}

Dengue fever is a disease caused by the dengue virus (DENV) by mosquito transmission by Aedes aegypti and Aedes albopictus (Stolp et al., 2015), which results in several symptoms ranging from mild fever to hemorrhagic dengue fever. The virus belongs to the family Flaviviridae and acts as the main cause of diseases arboviral (DENV1, DENV-2, DENV-3, and DENV-4) in tropical and subtropical regions (Sankarasubramanian, Pavithra, Kavitha, 2015), and new detection of DENV-5 (Mustafa et al., 2015), opening a new dilemma in disease control.

A 2013 estimate indicated that 390 million dengue infections each year, of which 96 million (67-136 million) manifest clinically (with any severity of the disease). There is a discrepancy between the dengue data estimated by the academic groups and those reported to the WHO, due to the lack of resources and the capacity to effectively research dengue, in addition to the fact that in many countries reports only confirmed cases in the laboratory, representing a small share of the total number of cases (WHO, 2018b).

Among the drugs developed for DENV activity are flavonoids, with research reporting several antiviral 
activities. In studies of Qamar et al. (2014), 2200 flavonoids (Figure 9) and docking analyzes of medicinal plants were performed on the NS1 protein block, calculating the possible active sites. The study resulted in 6 ligands, which showed strong interactions of the enzyme with the ligand, detecting the Asn-130 glycosylation of the NS1 target as a key binding site for activity.

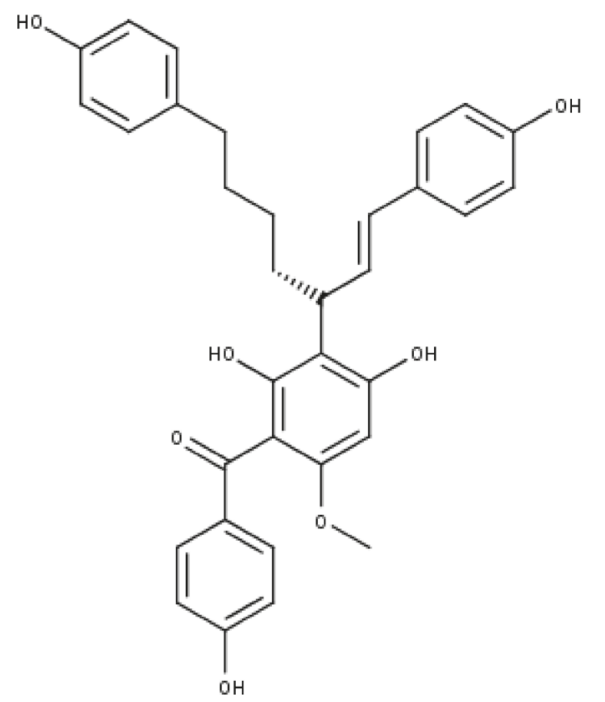

FIGURE 9 - Flavonoid reported in the literature because it has activity towards the NS1 enzyme.

Flavonoid activity for NS2B-NS3 enzymes has also been reported using molecular bioinformatics/docking tools, of which quercetin (Figure 10) has been shown to be the best inhibitor in the interactions with residues Asn 152, Ala 164, Lys 74, Asn 167, Leu 149, and Gly 87, as well as stability with the targets NS2B-NS3 (Senthilvel et al., 2013). Sousa et al. (2015) also demonstrated the action of flavonoids in the antiviral action of dengue, with activities ranging from 15 to $44 \mu \mathrm{M}$. In this same study, the molecular docking with the enzyme NS2B-NS3 was performed, in which all inhibitors were observed to bind in a similar way to the receptor, with the best interaction with the quercetin molecule.<smiles>O=c1c(O)c(-c2ccc(O)c(O)c2)oc2cc(O)cc(O)c12</smiles>

FIGURE 10 - Multi-target flavonoid that possessed an activity in the NS2B-NS3 complex.
In another article published by Vicentti et al. (2015), it has also been described the discovery of dengue virus inhibitors by means of virtual screening of ChEMBL for inhibitors of the enzyme c-SRC (Figure 11), which may be capable of interacting with the NS5 enzyme of the dengue virus. The collected compounds had $\mathrm{IC}_{50}$ activities lower than $100 \mu \mathrm{M}$, comparable to dasatinib and saracatinib. In this study, molecular docking analyzes (for 3000 thousand compounds) showed NS5 enzyme selectivity indexes better than the standard compound, blocking the formation of the NS3-NS5 viral complex and the inhibition of kinases c-SRC/Fyn of the host.<smiles>CNc1nc(Nc2cccc(O)c2)c2[nH]cnc2n1</smiles>

FIGURE 11 - Inhibitor of the enzyme c-SRC, which also acts on the DENV NS5 protein.

In the study carried out by Tambunan et al. (2011), a docking study with cyclic disulfide peptide ligands (Figure 12) in NS2B-NS3 enzymes for inhibition of virus growth was conducted. Among the ligands of the study, the compounds showed high affinities with the receptor, with formation of hydrogen bonds with Asp75 being the key link for the activity.

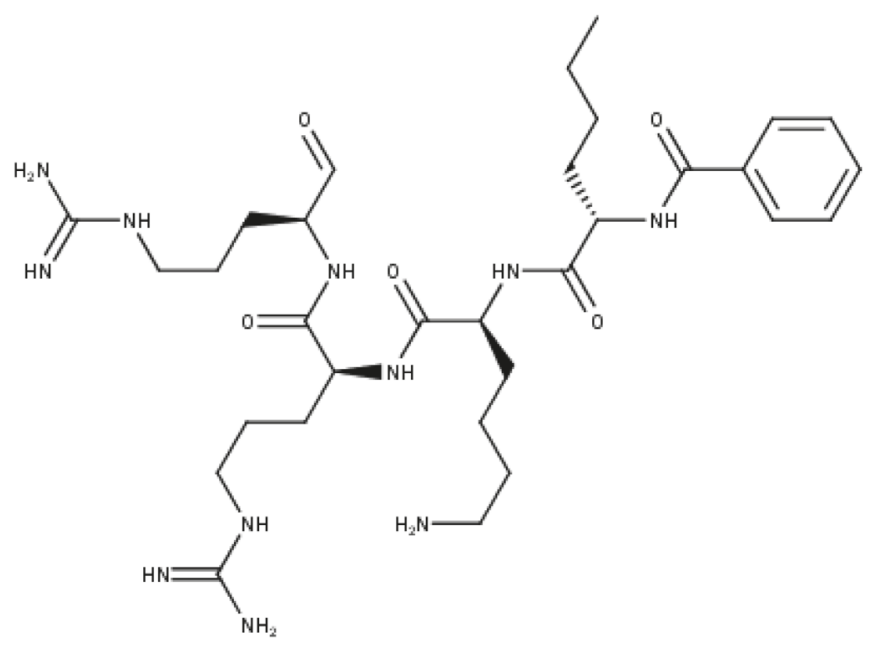

FIGURE 12 - Cyclic disulfide peptide ligand multi-target that acts on the NS2B-NS3 enzymes.

In another study, Borowski et al. (2002) evaluated the antiviral activity of several nucleosides, benzimidazole 
and ribose analogs with benzotriazole derivatives (Figure 13). These compounds showed considerable inhibition of the enzymes NTPase with $\mathrm{IC}_{50} 50 \mu \mathrm{M}$ and helicase at $3 \mu \mathrm{M}$.<smiles>COC1C(CO)OC(n2cnc3c(=O)[nH][nH]c(=O)c32)C1OC</smiles>

FIGURE 13 - Benzimidazole derivative targeting NTPase and helicase enzymes.

\section{NEURODEGENERATIVE DISEASES}

Neurodegenerative diseases have several problems in the medical field that need to be addressed because of their sharing of multifactorial mechanisms of action. Among the existing neurodegenerative diseases, we can mention: Alzheimer (AD), Parkinson (PD), Huntington (HD), and amyotrophic lateral sclerosis (ALS) (Lansbury, 2004). However, such diseases present clinical manifestations and mechanisms of action that converge among themselves, which involve the unfolding and aggregation of proteins, oxidative stress and the formation of free radicals, metallic dishomatosis, mitochondrial dysfunction, and phosphorylation impairment. Currently the term multitarget has been intensifying and solidifying studies in this area as a way to control the multiple targets responsible for the pathogenesis of the disease, known as Multi-Target Directed Ligands (MTDL) (Bishop, Sham, 2000; Morphy, Rankovic, 2007).

For example, Prati et al. (2015) described the triazinones (Figure 14) as multitarget molecules that may represent a promising starting point in developing lead compounds for Alzheimer disease. In the study it was reported that the triazinones can modulate the enzymes BACE-1 and GSK-3B simultaneously, with $\mathrm{IC}_{50}$ values ranging from $18-0.01 \mu \mathrm{M}$ on BACE- 1 and $14-0.78$ $\mu \mathrm{M}$ on GSK-3B. In studying the interactions through the molecular docking study of the compounds with both enzymes, they found that the compounds, mainly compound 3, acquired dual-target profiles because they had strong interactions with both enzymes tested.

Considering the deregulation of some specific proteins in Alzheimer disease, Zhang et al. (2012) conducted studies in silico and found that derivatives<smiles>CCCNC1=NC(c2ccc(CF)cc2)NC(=O)N1</smiles>

FIGURE 14 - Derivative triazinone that acts simultaneously on the enzymes BACE-1 and GSK-3B.

2-aminotiazoles (Figure 15) can act against the enzymes PARP-1 and BACE-1, with predictive activities that provided a basis for further development and structural optimization of novel potent inhibitors for the treatment of Alzheimer's disease.

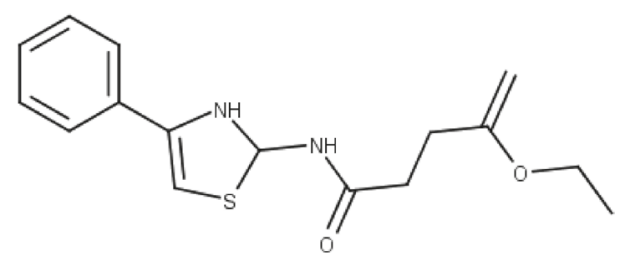

FIGURE 15 - Derivative 2-aminotiazole that can act on PARP-1 enzymes and BACE-1.

In another study, 67 hybrid molecules were designed with indole (Figure 16), and that by means of screening only 13 hybrids were selected that were submitted to molecular docking analysis of the enzymes PLA2, LOX-5, COX-2, and cholinesterase A and B (Dileep et al., 2013). As a result, when calculating their interaction energies, they observed that 3 hybrid compounds had strong interactions with the study targets, with better energy values compared to standard reference drugs.

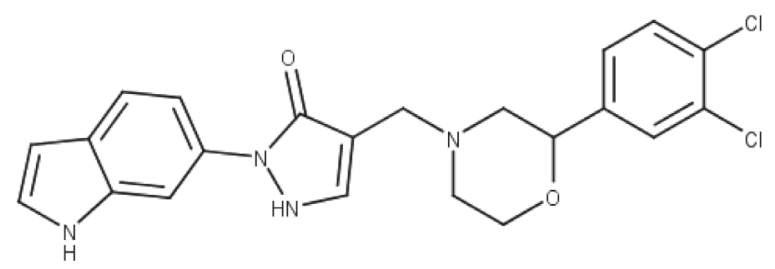

FIGURE 16 - Hybrid with an indole moiety reported to act on the enzymes PLA2, LOX-5, COX-2, and cholinesterase A and B.

In studies of Hui et al. (2014), they performed tests in silico and in vitro on various tacrine-phenothiazine derivatives (Figure 17) in the discovery of multitarget action. In their study they reported inhibitory compounds, with relevance to the compound T5, of the enzyme AChE, besides action of hyperphosphorylation of the enzyme tau and aggregation of beta amyloid. In another study in silico, Speck-Planche et al. (2013) analyzed 483 
compounds from a database and performed multi-target QSAR analyses using an LDA model. In their study, the descriptors were computed, and a model was constructed for the prediction of inhibitors that could act on proteins amyloid-A4 (ABPP), GSK-3 $\alpha$, GSK-3 $\beta$, MAO-B, and PS-1, all associated with Alzheimer disease.

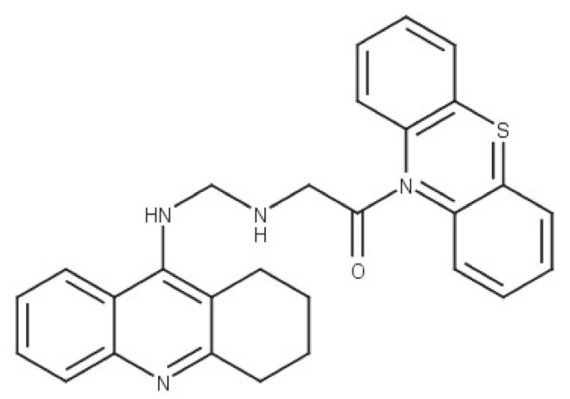

FIGURE 17 - Tacrine-phenothiazine derivative with multitarget action against the enzymes AChE, tau, amyloid-A4 (ABPP), GSK-3 $\alpha$, GSK-3 $\beta$, MAO-B, and PS-1.

In another study, a series of phenyl pyrazole derivatives (Figure 18) have been reported as inhibitors of acetylcholinesterase (AChE) and of monoamine oxidase $\mathrm{A}$ and $\mathrm{B}$ (MAO-A and $\mathrm{B}$ ), with selective activities in the micro and nanomolar range of $0.06 \mu \mathrm{M}$ to $\mathrm{AChE}$ and 2.69 $\mu \mathrm{M}$ to MAO A and B (Kumar et al., 2013). In the same study, structure-activity relationships were analyzed, where they showed that the derivatives with the chlorine moiety were more effective, but the molecular modeling data did not present in agreement with the experimental study, from which the strongest interactions occurred with the acetylcholinesterase.

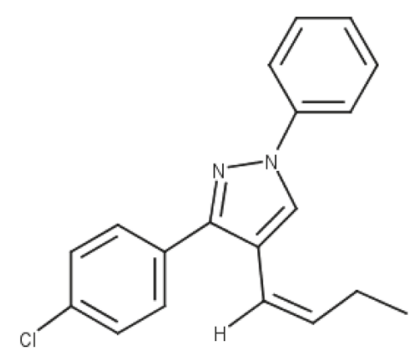

FIGURE 18 - Phenylpyrazole derivative that can inhibit the enzymes AChE and MAO A and B.

Among the natural compounds reported in the literature are baicalin (Figure 19), a flavonoid obtained from the plant Scutellaria baicalensis Georgi, which causes decreased activity of ONOO- and, successively, neurotoxicity (Xu et al., 2013) at a concentration of $10-50 \mathrm{mg} / \mathrm{kg}$. For the same compound, studies of its activity in the inhibition of the calcium influx NMDA and 5-lipoxigenase, which leads to a decrease in neuronal death, was found at a concentration of $1-5 \mu \mathrm{M}$ (Ge et al., 2007). In the studies carried out by Gao et al. (2013) in silico analysis of molecular docking and structure-based pharmacophore was performed, searching for activity against COMT and MAO-B proteins. In this study it was seen that baicalin has the potential to modulate the activity of the two proteins mentioned and guaranteed a protective role in neurotoxicity, but the activity of baicalin against the NMDA enzyme did not exhibit an inhibitory effect in a $[3 \mathrm{H}] \mathrm{MK}-801$ binding study.<smiles>O=C1CC(c2ccccc2)Oc2cc(O)c(O)c(O)c21</smiles>

FIGURE 19 - Baicalin, which has been reported in the literature to inhibit NMDA, 5-lipoxygenase, COMT, and MAO-B enzymes.

Another natural compound is huperzine A (Figure 20), an alkaloid isolated from Huperzia serrata, which acts as an inhibitor of acetilcolinesterase (AChE) ( $\mathrm{Li}$ et al., 2008; Wang, Yan, Tang, 2006), without promoting toxicity. Molecular docking studies demonstrated a higher specificity of interaction between AChE and huperzine A, of which the aromatic ring portion of the compound was responsible for the activity by binding to the aminophenol moiety of the enzyme, thereby promoting its inhibition (Yan et al., 2009). Inhibitory activities have also been reported for ROS enzymes at $0.1 \mathrm{mg} / \mathrm{kg}$ (Zheng, Zhang, Tang, 2008), NF-kiB at $0.1 \mathrm{mg} / \mathrm{kg}$ (Wang et al., 2008), and NMDA $10 \mathrm{nM}$ in calcium influx during neurotoxicity mechanisms (Gordon et al., 2001).

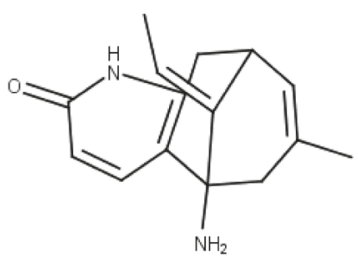

FIGURE 20 - Huperzine A acts as a multitarget by inhibition of AChE, ROS, NF-ḳB, and NMDA enzymes.

Honokiol (Figure 21) is derived from Magnolia grandiflora and has been shown to be a compound with multi-target characteristics acting in the blockade of the translocation of NF-kB and by inhibiting NO production in glial cells at a concentration of $0.7-70$ 
$\mathrm{mg} / \mathrm{kg}$ (Zhang et al., 2013). In addition to these targets, Cui et al. (2007) revealed the inhibition of NMDA mediated neurotoxicity. Honokiol has also been reported to stimulate the expression of ApoE, ABCA1, and ABCG1 in cells (Jung et al., 2010; Kotani et al., 2012). Besides these targets, it has also been reported to have activity against $A \beta$ through the regulation of autophagy, decreasing the phosphorylation of Akt and mTOR, and inhibiting $\gamma$-secretase through the negative regulation of the expression of the complex $\gamma$-secretase (Kaushik et al., 2012; Chang et al., 2013). In studies by Saeed et al. (2014) in silico molecular docking studies were investigated with the AKT kinase domain enzymes, STAT3 DNA binding domain, both mTOR complexes (mTORC1 and mTORC2), and both homologous MAPKKs (MEK1 and MEK2). In the study, it was seen that the compound bound to the same binding sites as the standard drugs erlotinib and gefitinib.

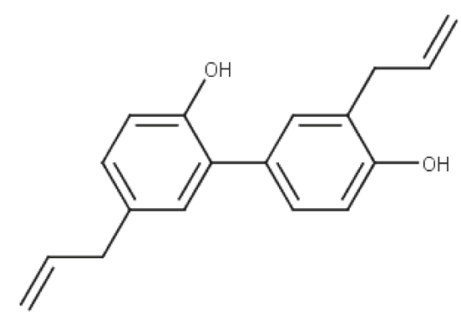

FIGURE 21 - Honokiol acts with multi-targeting activity by inhibiting the enzymes NF-kB, NMDA, $\gamma$-secretase, STAT3, mTORC1 and mTORC2, and MEK1 and MEK2.

\section{AIDS}

Studies on the human immunodeficiency virus (HIV-1), which causes acquired immunodeficiency syndrome (AIDS), have been of great interest to the pharmaceutical industry due to the high incidence of cases of infection (Jorissen et al., 2009) and due to the appearance of drug resistant strains. The use of antiretroviral drugs with unique targets is no longer recommended for clinical use, as drug resistant strains have appeared. A combination of antiretrovirals targeting different viral targets is required for better suppression of viral growth (Johnston, Hoth, 1993).

Liu et al. (2010) performed a multitarget quantitative structure-activity relationship (QSAR) study with human immunodeficiency virus (HIV-1), using a protease, integrase, and reverse transcriptase regression model. In this study, we presented a way to identify and even design inhibitors that couple to multiple targets in an efficient way, which determines the importance of this study, since the drugs used in the therapy concentrate, in the majority, on the inhibition of only a single target. The multi-target QSAR model was based on multi-task learning, where the three sets of target data with different percentages in training $(10 \%, 30 \%, 50 \%, 70 \%$, and $90 \%$ of the whole data) were used. Such a model was applied for the prediction of affinity. From the results found, a superiority of the multitarget QSAR under the single-target was observed, since they can take advantage (this can be seen more clearly, in small datasets) of the multi-task learning synergy and can take advantage of the synergy among tasks when the label data on each single task are insufficient.

Thus, the authors conclude that multitarget virtual screening with a multi-task learning paradigm can facilitate the identification of leads for HIV-1 inhibitors, besides reducing time, effort, and cost to obtain compounds to be evaluated for their activity and efficacy in the treatment of AIDS.

In a study carried out by Speck-Planche et al. (2012) (C-C chemokine receptor type 2, C-C chemokine receptor type 5, C-X-C chemokine receptor type 2, C-C chemokine receptor type 4, retroviral aspartyl protease, reverse transcriptase, retroviral integrase), two mt-QSAR models were developed starting from a large and heterogeneous bank of compounds where for each protein a cut-off value of inhibitory activity was considered. For the first model, a linear discriminant analysis (mt-QSAR-LDA) was used by the use of fragments-based descriptors, the best model presented 16 descriptors (Equation 1). Artificial neural networks (mt-QSAR-ANN) were used for the development of the second model, with the best model presenting the following RBF profile 11: 11-293-1: 1 .

$$
\begin{aligned}
& \mathrm{A}_{\text {HIV-IP }}=-0.607(\mathrm{R}=\mathrm{Ct})-1.843(\mathrm{ArOCON})+1.299(\mathrm{RCO}) \\
& +0.666(\mathrm{ArCO})-1.426(\mathrm{RC}=\mathrm{N})+1.597(\mathrm{ArCN}) \\
& +0.722(\mathrm{Pyrld})+0.700(\mathrm{C}-027)+0.769(\mathrm{C}-041) \\
& -0.306(\mathrm{O}-060)+0.538(\mathrm{~N}-075)+0.484(\mathrm{~F}-084) \\
& +4.427 \times 10^{-4} \mu_{5}^{(\mathrm{Std})}-0.021 \mathrm{avg} \mu_{3}^{(\mathrm{Ab}-\mathrm{sumB} 20)} \\
& +0.414 \operatorname{dif} \mu_{1}^{(\mathrm{Gas})}-1.286 \times 10^{-5} \mathrm{dif} \mu_{9}^{(\mathrm{Ab}-\mathrm{R} 2)}-2.250 \\
& \mathrm{~N}=1341 \quad \lambda=0.381 \quad X^{2}=1284.93 \quad F_{(16,1324)}=134.54 \\
& p<0.001
\end{aligned}
$$

It was observed that the generated models correctly classified more than $90 \%$ of active and inactive compounds for the training and prediction. Thus, new molecules designed from fragments with positive contributions were analyzed in the models produced and were correctly predicted as possible anti-HIV agents, where for the mt-QSAR-LDA model the probability of all molecules being anti-HIV was high. The results of the forecasts for 
the mt-QSAR-ANN model confirmed that in 40 of the 42 cases $(95.24 \%)$, the forecast could be correct. This fact demonstrates that all new molecules (especially compounds of MTI-2 to MTI-5 (Figure 22)) can be considered possible anti-HIV agents acting on the cited targets.

In addition, a new model of linear regression based on the similarity of the genetic function was developed by Edache et al. (2016), who performed a multi-target quantitative structure-activity relationship (mt-QSAR) study with immunodeficiency virus and using data sets of inhibitors (containing 150 compounds with well-defined activity) (Edache, Uzairu, Abechi (2015), Luco, Ferretti (1997)), aimed at integrase and reverse transcriptase.

These compounds were designed and minimized by the Spartan'14 (2013) version 1.1.2 (Wavefunction, 2013) using molecular mechanics (MMFF) and had descriptors calculated by PaDEL-Descriptors version 2.18 (885 in total) (Yap, 2011). The most significant models are illustrated below:

\section{Model 1:}

PIC $_{50}=3.08172(+/-0.52134)+3.09393(+/-0.52028)$ ATSc $3+28.05602(+/-3.2988) S C H-3-34.91622$ $(+/-3.30279) \mathrm{VCH}-7-13.37449(+/-1.35611) \mathrm{VC}-5$ $+3.67308(+/-0.18491) V P C-5-0.76154(+/-0.08721)$ $n H B d-2.48376(+/-0.49227) n d d s S S-0.24588$ $(+/-0.04857)$ minHBint5 (2)

$N=120, L O F=1.7850, R=0.9658, R_{\text {train }}^{2}=0.9329, R_{a d j}^{2}=$ $0.9280, Q_{c v}^{2}=0.9065, F-$ test $=192.7484, S E E=0.6557$, $Q=1.4729, P R E S S=66.4307, S D E P=0.7440, \mathrm{r}_{\text {test }}^{2}=$ $0.8929, \mathrm{r}_{0}^{2}=0.8891, \mathrm{r}^{\prime 2}{ }_{0}=0.8911$

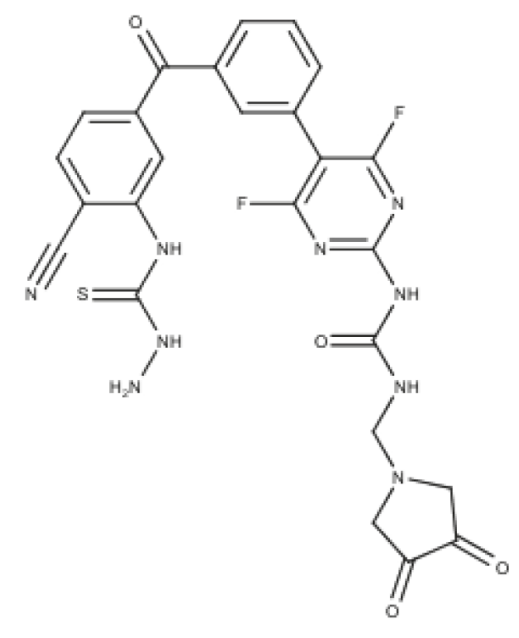

1

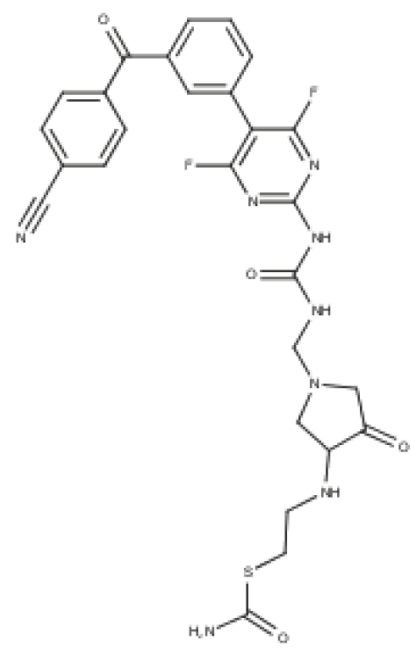

3

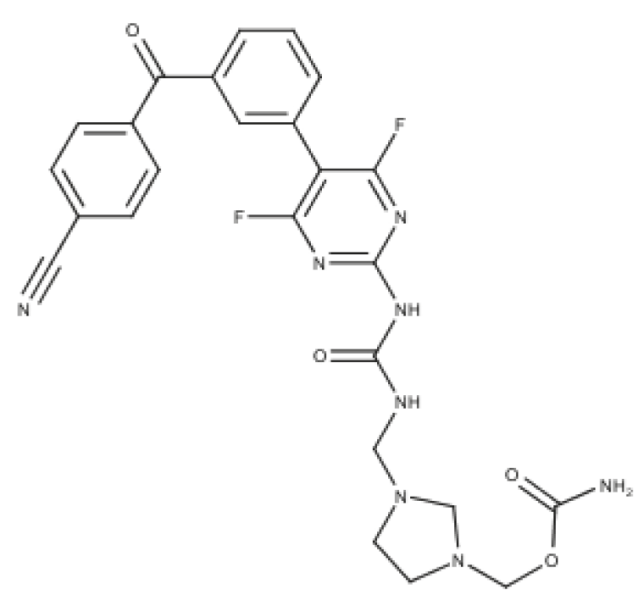

2

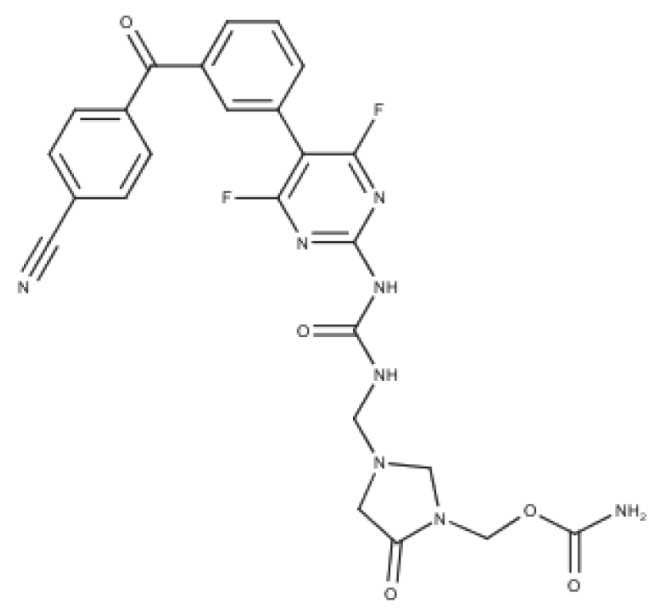

4

FIGURE 22 - Four best molecules suggested as possible versatile anti-HIV agents (MTI-2 to MTI-5, numbered 1-4, respectively). 


\section{Model 2:}

$P I C_{50}=3.35843(+/-0.50132)+3.45359(+/-0.5738)$ ATSc3 + 26.16473 (+/-3.20745) SCH $-3-32.26124$ $(+/-3.02354) \mathrm{VCH}-7-13.26959(+/-1.37737) \mathrm{VC}-5$ $+3.57781(+/-0.18586) V C P-5-0.43222(+/-0.08688)$ $n H B d-0.18283(+/-0.03768)$ maxHBint $5+$ $0.56005(+/-0.10593) \operatorname{gmin}(3)$

$N=120, L O F=1.8483, R=0.9648, R_{\text {train }}^{2}=0.9305, R_{a d j}^{2}$ $=0.9255, Q_{c v}^{2}=0.9108, F-$ test $=185.6753, S E E=$ $0.6672, Q=1.4460, P R E S S=63.3978, S D E P=0.7269$, $\mathrm{r}_{\text {test }}^{2}=0.9039, \mathrm{r}_{0}^{2}=0.9024, \mathrm{r}^{\prime 2}=0.901$

According to the authors, the constructed models were robust and satisfactory, and the descriptors could explain the characteristics responsible for inhibition of HIV.

Zhang et al. (2006) performed a double mutant reverse transcriptase $(\mathrm{K} 103 \mathrm{~N})$ and wild type (WT) inhibitor assay. The molecular docking and 3D-QSAR approaches were applied to a set of twenty-five 4,1-benzoxazepinone efavirenz analogs (SUSTIVA ${ }^{\circledR}$ ) (Figure 23). The CoMFA and CoMSIA models have reasonably high $\mathrm{r}_{\mathrm{cv}}^{2}$ values ranging from 0.656 to 0.834 for type WT and K103N, respectively. From the validation, it was concluded that both models are predictive and extrapolative. In more detail, the authors reported that CoMFA analysis has shown that steric interactions are the main inhibitory factor for WT. However, CoMSIA analysis demonstrated that the donor effects of steric, electrostatic, and hydrogenated bonds present the same contributions for the binding of inhibitors to K103N.

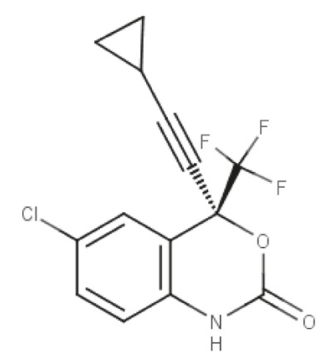

FIGURE 23 - Structure of efavirenz.

Based on this study, it was possible to better understand the interaction of the compounds evaluated with the WT and K103N reverse transcriptase, favoring the choice of a pharmacophore for the compounds and the design of new double inhibitors.

\section{CANCER}

Prostate cancer (PC) is the most common diagnosis of cancer among men and the second leading cause of cancer death. Several forms of treatment for the local tumor have been widely used (Arshad et al., 2017). However, when invasion occurs to other organs, conventional treatment is not always effective. The search for potent anti-PC agents is a challenge. In recent years, several computer-aided design methodologies (CADD) have contributed to the search for compounds with antiPC activity. However, these methodologies do not always have advantages, as they generally reach only one PC cell line or only one target as the PC-associated protein. In this sense, Speck-Planche et al. (2011), developed the first multi-target approach for the planning and prediction of anti-PC agents against several cell lines. This planning represents a fragment-based QSAR model using a heterogeneous database of compounds for the efficient and rapid extraction of substructures responsible for anti-PC activity depending on the type of PC cell line.

The fragmented QSAR model, according to the authors, is expressed in functional group counting descriptors (CGF), which contain fragmentary characteristics of specific functional groups in a molecule and is calculated from the molecular composition and atom of connectivity. A set of 816 compounds with antiPC activity against four PC cell lines (CWR22R, LAPC4, LNCaP, and PC-3) were analyzed and the CGFs calculated using DRAGON v5.3.11. The spectral moments of the weighted binding adjacency matrix (TOPS-MODE of order 1 to 15) were calculated using MODESLAB v1.5.37. Linear Discriminant Analysis (LDA) was used to construct the classifier model.

The results showed that the number of variables did not significantly improve the quality of the model, whereas a decrease in the number of variables improved the quality and predictive ability. The sensitivity of the model was $88.36 \%$ and the specificity was $94.06 \%$ in the series formation, to an accuracy of $91.28 \%$. The sensitivity of the model in prediction series was $89.81 \%$ and the specificity was $92.92 \%$, with precision of $91.39 \%$. The ROC curves were 0.97 for both training and forecast series. In this sense, six molecules were considered favorable in relation to fragments for anti-PC activity (Figure 24).

Another study that sought potent anti-PC multitarget agents was carried out by Ban et al. (2017). The study integrated a number of molecular modeling techniques available with a series of experimental tools to successfully develop a new class of potent selective androgen receptor inhibitors with a new mode of action (Ban et al., 2017). The differential of this study was the favorable screening of regions ideal for drug planning. Because human androgen (RA) receptors are considered master regulators for prostate cancer and the cancer cells often become 
<smiles>O=[N+]([O-])c1cc(Br)cc(C2C=NC=NC2)c1</smiles>

M1<smiles>O=[N+]([O-])c1cc(-c2cc[nH]n2)cc(C2C=NC=NC2)c1</smiles>

M6<smiles>O=[N+]([O-])c1cc(C2=NCCS2)cc(C2C=NC=NC2)c1</smiles>

M2<smiles>O=[N+]([O-])c1cc(-c2ccon2)cc(C2C=NC=NC2)c1</smiles>

M3<smiles>O=[N+]([O-])c1cc(-c2ccc[nH]2)cc(C2C=NC=NC2)c1</smiles>

M7<smiles>O=[N+]([O-])c1cc(-c2cc(Br)c[nH]2)cc(C2C=NC=NC2)c1</smiles>

M8

FIGURE 24 - Molecules considered favorable in relation to fragments for anti-PC activity.

resistant to the drugs used to inhibit these receptors, the researchers in this study developed AR-driven drugs with a completely new mode of action. To do this, they used molecular modeling techniques that allow the exploration of all viable small molecule binding sites on the surface of RA. They used the Molecular Operating Environment (MOE), a software package 27 used for many modeling tasks, and a protein database (APO) to examine deposited structures of the ligand binding domain (LBD) of the AR (ID PDB: 2PIO), as well as the DNA binding of the receptor domain (DBD) (ID PBR 1R4I).

Conventional molecular graphics tools such as MOE and Maestro were used to explore those in RA to identify mutations and to verify conserved and non-conserved regions that outweigh drug resistance for the planning of new drugs. In this article, we present the structure-based virtual screening (SBVS) using GLIDE (Friesner et al., 2004, Halgren et al., 2004, Friesner et al., 2006) and ligand-based virtual classification through QSAR 4D that accurately describes and quantifies important structural aspects involved in mutant drug interactions (Paul et al., 2016). The most active compound, 4- (4-phenylthiazol-2yl) -morpholine (vpc14228) (Figure 25) demonstrated an $\mathrm{IC}_{50}$ of $\sim 0.5 \mu \mathrm{M}$ in GFP assays and for PSA was considered by the study to be the most promising candidate for more detailed evaluation of a multi-target effect.

Another important step was lead optimization, which represents another critical step in a drug in the discovery process. The main goal of successful optimization of a lead is to turn a prospective compound into a clinical candidate through iterative cycles of CADD-assisted design, medicinal chemistry (Medchem), and experimental evaluation. To help develop a suitable synthetic strategy, they used the ADMET Predictor 7.2 software (Steinbrecher, 2015). Thirty-four analogs of vpc14228 have been synthesized wherein the phenyl ring has been substituted by heterocycles or modified with several substituents. Of the compounds developed, 21 demonstrated sufficient anti-RA activity (eGFP IC50<10 $\mu \mathrm{M}$ ), where six of them exceeded the value of vpc14228 and the synthetic analog vpc14449 with 2,4-dibromoimidazole showing a modest improvement in potency over vpc14228.

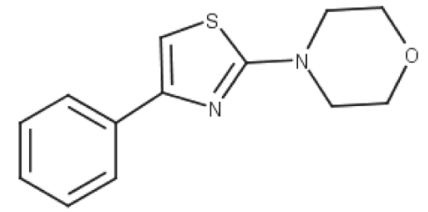

FIGURE 25 - Structure of the compound 4-(4-phenylthiazol-2yl)-morpholine (vpc14228).

In general, CADD techniques and methodologies for the development of multi-target compounds as 
anticancer agents are targeted at crucial targets in tumor transformation and progression and not for a particular type of cancer. There are some types of cancer that are a specific case, but cancer is considered a multifactorial disease. For example, there is a need to inhibit or reduce the action of side effects on various organs and also reduce drug resistance by various targets.

A multitarget agent has been increasingly explored as targeted anticancer agents (Pilpel, Sudarsanam, Church, 2001; Muller, 2004; Keith, Borisy, Stockwell, 2005; Christopher, Overall, 2006; Sergina et al., 2007) to achieve therapeutic efficacy. Several successful multi-target drugs in cancer treatment are sunitinib against PDGFR and VEGFR, dasatinib against ABL and SRC, and lapatinib against EGFR and HER2 (Gill et al., 2007; Krug, Hilgerot, 2008).

Ma et al. (2010) rate a virtual tracing method using vector support machines (SVM) for their performance in the search of dual inhibitors using large library partnerships in the PubChem Database and the active agents of the MDR database. The SVM of each of the six anticancer targets EGFR, FGFR, VEGFR, PDGFR, SRC, and LCK kinases. Double inhibitor recovery rates were 40.9\% for EGFR-FGFR, 52.6\% for VEGFR-LCK, 38.3\% for PDGFR-SRC, and 48.2\% for SRC-LCK, respectively. Thus, combinatorial SVMs show reasonably good ability to selectively identify multi-target agents.

Marzaro et al. (2011) reported the importance of tyrosine kinases (TK) as important targets in cancer development and explored potential strategies to inhibit these receptors. The work focuses on relevancy for the development of multi-target drugs, since most inhibitors are designed to be selective against a single TK or at the most two. Like Ma et al. (2010), Marzaro (2011) also used SMV to identify multitarget drugs. A set of data for generation of mtc-QSAR models were constructed. The structure and biological data of 1300 consisting of TCT, 3 cytoplasmic TKs (ABL, LCK, and SRC), and 5 TK receptors (EGFR, FGFR1, KDR, PDGFR $\beta$, and VEGFR-1). The compounds were tested against more than one TK. To evaluate the efficacy of the prediction, the selected models were asked to classify a set of 13 known compounds. The results showed a high degree of structural variability and presented a wide range of activities (from 3 $\mathrm{pM}$ to up to $100 \mu \mathrm{M}$ ). In addition, five QSAR multitarget models for the classification of TKIs was developed. Due to the good accuracy of the model, this model may be useful for finding new inhibitors of kinases.

Li et al. (2011) investigated multi-target anticancer inhibitors for EGFR, VEGFR-2, and PDGFR. In this study, two virtual selection methods were selected for the choice of compounds to be tested as potent multi-target inhibitors, vector support machines (SVM) and molecular coupling. The compounds were withdrawn from the PubChem database and through virtual screening, three compounds derived from benzimidazole were identified as potent inhibitors. A series of compounds derived from benzimidazole identified in the virtual screening were synthesized and evaluated for biological activity. Specifically, compound 47037197 (Figure 26) identified in the screen showed inhibition against two receptors, EGFR and VEGFR. All benzimidazole derivative compounds that were synthesized showed anticancer activity. In this way, the study contributed to discover a new class of anticancer compounds.

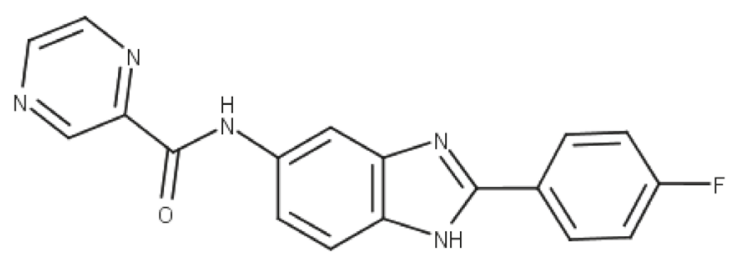

FIGURE 26 - Structure of the compound PubChem ID 47037197.

Several other researches have also investigated receptor kinases as potent targets for the discovery and design of multi-target agents. Luan et al. (2011) analyzed a series of 21 acridine derivatives, which were synthesized and evaluated for their antiproliferative activity against K562, HepG-2, and MCF-7 cells. The molecular docking study as well as the results of inhibition of kinase in vitro assays indicated that compound $7 \mathrm{r}$ (Figure 27) may be a potent inhibitor of VEGFR-2 and SRC. They have also suggested that acridine, which has been used historically to inhibit topoisomerases, is a potentially interesting compound for inhibiting receptor kinases.

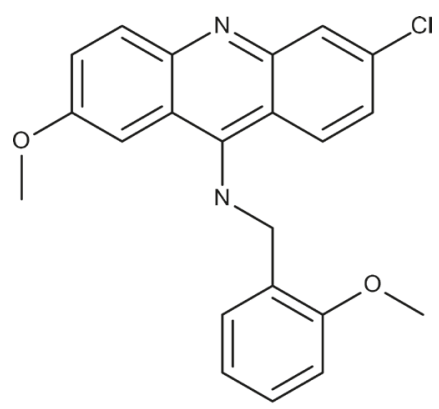

FIGURE 27 - Compound $7 \mathrm{r}$ reported in the literature for inhibiting the enzymes VEGFR-2 and SRC.

Other targets have also been cited in the literature as important strategies in the rational planning of multi-target 
drugs for cancer treatment. Ning et al. (2015) has found from literature data that the inhibitor pacpirinib (SB1518) of JAK2 is reported to exert cytotoxic effects against cell lines bearing mutations JAK2v617f and FLT3-ITD. Anchorage studies showed that SB1317 binds to FLT3 and JAK2 through the hydrogen bonding interactions with residues (Cys694 to FLT3 and Leu932 to JAK2) in the hinge region. It is known that HDAC interacts with FLT3 and JAK2; Ning et al., (2015) proposed structural modifications in HDAC inhibitors in order to inhibit the complex without compromising binding between FLT3 and JAK2. Docking studies were conducted to identify the best interactions between targets and compounds. This was the first study to explore the design, synthesis, and evaluation of a single chemical entity that can simultaneously inhibit HDAC, FLT3, and JAK2. Thus, a number of target compounds have been carefully constructed by combining these structural features based on SB1317 and SB1518 macrocycle models. Most of these macrocycles have been shown to exhibit potent inhibition of HDAC as well as inhibition of FLT3 and JAK2. The research suggests that compound 32 (Figure 28) is the newest multi-targeting agent for HDAC, FLT3, and JAK2.

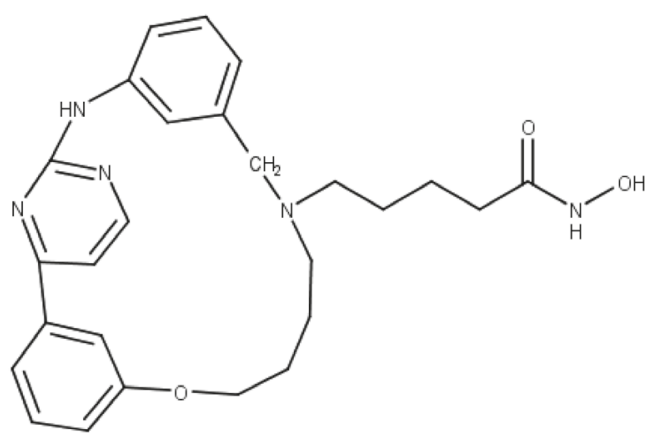

FIGURE 28 - Structure of compound 32, the most active inhibitor against HDAC, FLT3, and JAK2.

Schmidt et al. (2015) also investigated another class of inhibitors, the G protein-coupled receptors (GPRC). GPRCs are often responsible for signal transduction and are involved in several pathologies such as cancer. Thus, they proposed to prospectively identify ligands for two proteins through the fitting and predict their binding pattern. Despite the study using common computational techniques, the way they were applied reflects their differential in the search for multi-target drugs. The authors verified from the literature that the chemokine receptors CXCR3 and CXCR4 have a synergistic effect, which means that simultaneous blocking of both receptors could have a superior pharmacological effect compared to inhibition of any receptor. The ChEMBL database (version 17) recorded 858 and 484 binders tested against CXCR3 and CXCR4, respectively. Several resources were used in the study, among them, virtual screening based on structure, molecular docking, and molecular modeling by homology, among others. After inspecting the best anchored poses, four compounds were predicted to bind to both selected receptors. However, two of these four, compounds a and b (Figure 29), were considered active in both receptors according to the assays performed. Thus, the studied presented new CXCR3-CXCR4 double modulators that may aid in understanding the mechanisms of polypharmacological inhibition of these receptors.

Espinoza-Fonseca (2005) also studied other rather interesting targets for cancer, the tumor suppressor protein p53 and its negative regulator MDM2. p53 is responsible for the response to a range of cell lesions and is one of the main mediators of cell cycle arrest and the activation of apoptosis (Vogelstein, Lane, Levine, 2000). The aim of this study was to demonstrate that RITA, a drug originally found to bind to the p53 tumor suppressor, is also capable of binding MDM2-p53 transactivation, increasing its efficacy and making it a standard compound for cancer drug design. In using molecular docking, the authors discovered that RITA binds preferentially to the MDM2-p53 transactivation domain binding cleft. Thus, RITA was considered a multi-target compound for MDM2 and $\mathrm{p} 53$ and a possible standard compound for the rational planning of multi-target and anticancer drugs.

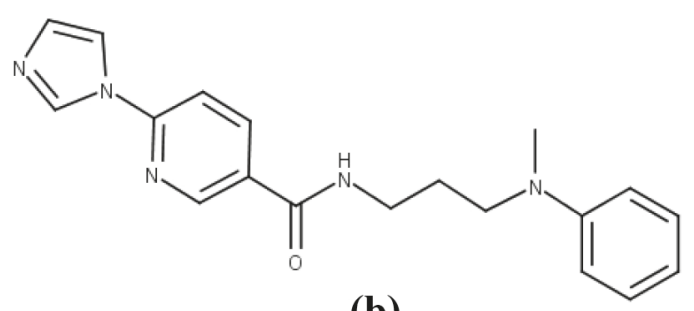

(b)

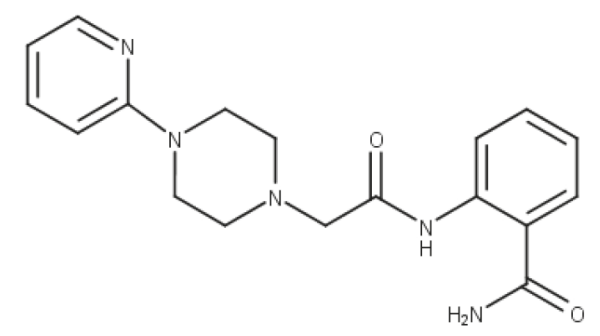

(a)

FIGURE 29 - Structures of compounds a and b, inhibitors of the CXCR3-CXCR4 complex. 
New docking strategies to show target binding were tested and validated by Szelag et al. (2015). The study sought current strategies for modeling and selecting STAT inhibitors (signal transducer and activator of transcription) based on SH2. SH2 is a highly conserved domain that interacts with phosphotyrosine motifs for specific STAT receptor contacts and STAT dimerization, mediating a series of responses that when abnormal, implicate in the development of cancer and inflammation. Although a number of small molecules are known, many of them are not STAT3, specific from a six-membered family (STAT1, STAT2, STAT3, STAT4, STAT5A, STAT5B, and STAT6).

The study generated 3D structure models for all human STATs through homology modeling and performed coupling to obtain more information on the STAT-SH2 cross-linking specificity of a previously identified STAT3 inhibitor selection. The comparative affinity value of STAT and the variation of ligand binding pose were the criteria for the selection of inhibitors specific for STAT3 as a new tool for virtual verification and validation. The ligand-based approach was used to generate a protomol molecular probe which is a $3 \mathrm{D}$ representation of the active site to which the ligands are combined, in this case in the STAT-SH2 region corresponding to the selected sub-pockets. The results showed that the affinity values of the STAT3 binding were the highest for the natural compounds: Cucurbitacin Q $>$ Curcumin $>$ Cucurbitacin E $(9.08,7.89,7.49$, respectively). Only the natural compounds cucurbitacin Q (for STAT2 and STAT5A) and Curcumin (for STAT5A) exhibited a certain degree of specificity for STAT3.

Yousuf et al. (2017) conducted a study based on virtual screening, molecular docking, and ADMET properties to propose new multitarget inhibitors for breast cancer. In this study initially $\sim 3$ million compounds were extracted from different databases, such as E-molecule databases and chemical companies including Pub-Chem and Active ZINC. All of the compounds extracted from these databases were submitted to different filters (LRo5, drug likeness, PK filters) to identify anti-breast cancer compounds, selecting the best 66,832 compounds. These compounds were subjected to structure-based virtual screening (SBVS) against EGFR, HER2, and HSP90 separately to identify multi-targeted compounds common among all these targets using the software AutodockVina. Getting 96 top virtual hits against EGFR, 114 top virtual hits against HER2, and 79 top virtual hits against HSP90.

The ligands were also analyzed for their profile of absorption, distribution, metabolism, excretion, and toxicity (ADMET), which determined the ADMET efficiency of the drug. Potential hits that indicate good pharmacokinetic (PK) and pharmacodynamic (PD) properties have a better chance to be effective future drugs. The results of the current study concluded that five multi-targeted compounds (S-258282355, S-258012947, S-259417539, S-258002927, and S-259411474) (Figure 30) with high binding energies that range between -8.7 to $-10.3 \mathrm{kcal} / \mathrm{mol}$ as well as a good ADMET profile against all three targets be taken into consideration, suggesting them as potential hits for drug development against breast cancer after testing through in vitro and in vivo experiments.

Zhou et al. (2017) used a computer-aided rational drug design approach that led to the synthesis and characterization of CS2164 (N-(2-aminophenyl)-6-[(7methoxy-4-quinolinyl)oxy]-1-naphthalenecarboxamide, Figure 31) and evaluated as a novel multi-kinase inhibitor through the in vitro studies and the molecular docking.

CS2164 inhibited VEGFR2, Aurora B and CSF$1 \mathrm{R}$ kinases with very high potency $\left(\mathrm{IC}_{50}=7,9\right.$ and 7 $\mathrm{nM}$, respectively). CS2164 also displayed inhibitory activities with single digital nanomolar $\mathrm{IC}_{50}$ against several angiogenesis-related kinases, including VEGFR1, VEGFR3, PDGFRa and c-Kit. The $\mathrm{IC}_{50}$ for PDGFRb inhibition was tested as $93 \mathrm{nM}$. CS2164 only showed moderate inhibitory activities $\left(100 \mathrm{nM}<\mathrm{IC}_{50}<500 \mathrm{nM}\right)$ in 4 kinases (c-RAF, DDR2, PLK1 and PLK3), little activity $($ IC50 $>500 \mathrm{nM})$ in 33 kinases, and almost no activity $\left(\mathrm{IC}_{50}>10 \mu \mathrm{M}\right)$ in over 120 kinases, including 76 GPCR and 8 ion channels tested. Thus, these results indicate that CS2164 is a novel small molecule inhibitor with selective and potent inhibitory activities in VEGFR/Aurora B/ CSF-1R kinases. Consequently, CS2164 displayed antiangiogenic activity through suppression of VEGFR/ PDGFR phosphorylation, inhibition of ligand-dependent cell proliferation and capillary tube formation, and prevention of vasculature formation in tumor tissues. The molecular docking studies showed that CS2164 interacts with each active ATP binding pocket of VEGFR2, aurora $\mathrm{B}$ and CSF-1R kinases, respectively. Thus, it is being considered a potential candidate for cancer therapy as a multitarget agent.

Yuan et al. (2017) have performed the synthesis of new compounds derived from olaparib's hydroxycinnamic acid derivative (the first FDA approved PARP inhibitor, poly (ADP-ribose) polymerase for patients with ovarian cancer with BRCA mutations), as well as evaluated its anti-tumor activity in vitro on seven different human tumor cell lines including breast cancer (T47D, MCF-7, and MDA-MB-231), lung cancer (HCC827), cervical cancer (HeLa), leukemia (K562), and lymphoma (U937) cell lines using an MTT assay. 
<smiles>O=C(COC(=O)c1cccc(OC(F)F)c1)Nc1ccc2ccccc2c1</smiles>

(a)<smiles>COc1ccccc1C1N=NC(SC2c3ccccc3-c3ccccc32)O1</smiles>

(c)

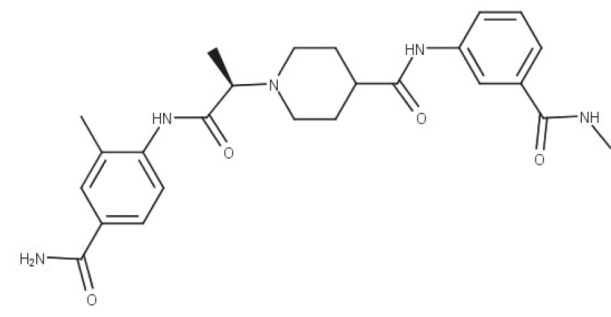

(b)<smiles>O=C(CCCCCc1nc(=O)c2ccccc2[nH]1)Nc1ccc(Br)c(C(F)(F)F)c1</smiles>

(d)<smiles>C[C@H](NC(=O)[C@H]1CCCC1S(=O)(=O)c1ccc2c(c1)OCCO2)c1cccc(F)c1</smiles>

(e)

FIGURE 30 - Chemical structures of lead compounds: (a) S-258002927; (b) S-258012947; (c) S-258282355; (d) S-259411474; (e) S-259417539.<smiles>COc1ccc2c(Oc3ccc4c(C(=O)Nc5ccccc5N)cccc4c3)ccnc2c1</smiles>

FIGURE 31 - Chemical structure of CS2164.

Based on the rational strategy of drug design, the hydroxamic acid derivatives of olaparib were constructed as partial inhibitors of PARP and HDAC. Four new hybrids were synthesized (Figure 32). These hybrid compounds showed potent inhibitory activities against PARP $1 / 2$ and $\mathrm{HDAC} 1 / 6$ with values of $\mathrm{IC}_{50}$ in the nanomolar range (between 2,53 and $912.50 \mathrm{nM}$ ).
In addition, compound $\mathrm{P} 1$ exhibited broad spectrum antiproliferative activities against selected human cancer cell lines (between 0,22 and 8,65 $\mu \mathrm{M}$ ). Especially, P1 showed more potent activity than olaparib and SAHA against cancer cells MDA-MB-231, HCC1937, and Raji, and 4.1-fold less cytotoxicity compared to SAHA for normal MCF-10A cells.

Another mechanistic study has indicated that P1 can induce PARP cleavage and histone hyperacetylation, increase biomarker expression of c-H2AX DNA damage, decrease BRCA1 and RAD51 levels, and regulate tumor cell growth and apoptosis through mitochondrial cell modulation and pathways mediated by death receptors. Therefore, our study suggested that compounds targeting PARP and HDAC simultaneously may be a practical approach to multitarget cancer therapy.

The above docking results may further confirm the inhibitory potency of $\mathrm{P} 1$ and $\mathrm{P} 2$ against PARP and HDAC. Thus, dual PARP and HDAC inhibitors, and 
$\mathrm{P} 1 / \mathrm{P} 2$ represent promising lead compounds for further optimization to develop novel antitumor agents.

Mayank and Jaitak (2016) investigated in silico the anticancer potential of alkaloids. Alkaloids are natural molecules that can be developed as multi-targeting inhibitors of the hedgehog $(\mathrm{Hh})$ pathway. The Hh pathway is a developmental pathway that plays an active role in various developmental processes, such as cell fate, proliferation, survival, and differentiation. Up-regulation of the Hh pathway was found to be significantly associated with multiple forms of cancers along with its involvement in CSC maintenance.<smiles>O=C(/C=C/c1ccc(CCNC(=O)c2cc(Cc3n[nH]c(=O)c4ccccc34)ccc2F)cc1)NO</smiles>

P1<smiles>O=C(Cc1ccc(CN2CCN(C(=O)c3cc(Cc4n[nH]c(=O)c5ccccc45)ccc3F)CC2)cc1)NO</smiles>

P3
The alkaloids that were chosen were previously reported to have significant anticancer potential and further exploration of them from a mechanistic prospective may provide us a good anticancer lead molecule. Fortyfive alkaloids were screened in this study. The screening performed with molecular docking resulted in five lead compounds: 1 emetine, $\mathbf{2}$ cortistatin, $\mathbf{3}$ solamargine, $\mathbf{4}$ solasonine, and 5 tylophorine (Figure 33).

The in silico experimental data indicated that emetine and cortistatin have the ability to modulate the $\mathrm{Hh}$ pathway by binding to sonic hedgehog $(\mathrm{Hh})$, smoothened (Smo), and Gli protein, involved in the maintenance of<smiles>CNC(=O)/C=C/c1ccc(CN2CCN(C(=O)c3cc(Cc4n[nH]c(=O)c5ccccc45)ccc3F)CC2)cc1</smiles>

P2<smiles>O=C(NO)c1ccc(CN2CCN(C(=O)c3cc(Cc4n[nH]c(=O)c5ccccc45)ccc3F)CC2)cc1</smiles>

P4

FIGURE 32 - Synthesis of designed dual PARP and HDAC inhibitors P1-P4.

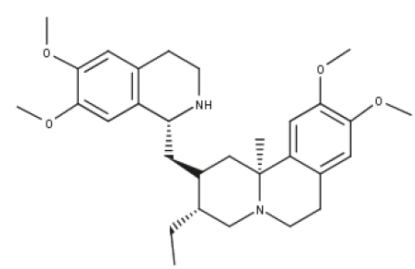

(1)

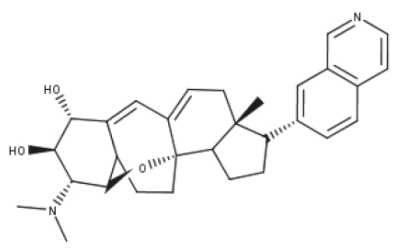

(2)

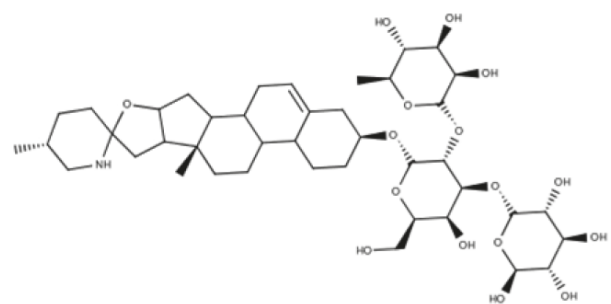

(3)

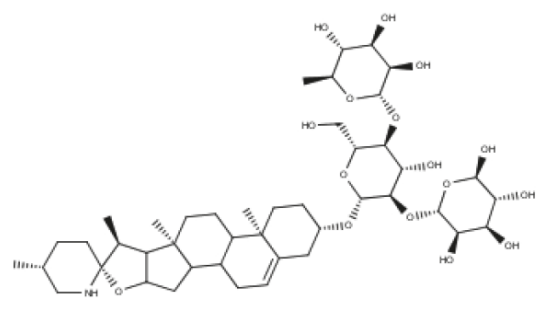

(4)

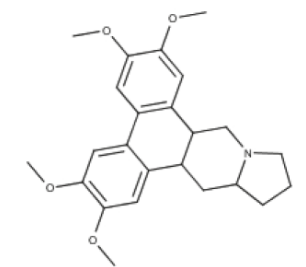

(5)

FIGURE 33 - Chemical structure of lead compounds: $\mathbf{1}$ emetine, $\mathbf{2}$ cortistatin, $\mathbf{3}$ solamargine, $\mathbf{4}$ solasonine, and $\mathbf{5}$ tylophorine. 
cancer stem cells (CSCs). Furthermore, solamargine, solasonine, and tylophorine also seems to be good lead molecules targeting towards CSCs by modulating the Hh pathway. In addition to solamargine and solasonine, other best lead molecules also showed an acceptable in silico ADME profile. The predicted lead molecules can be suitably modified to obtain multitargeting CSC targeting agents to get rid of associated resistance.

Singh and Bast (2015) performed studies to discover multi-target natural compounds for receptor tyrosine kinase inhibitors and biological evaluation of cancer cell lines by employing in silico and in vitro approaches. A dataset of 50000 ligands were used in this study obtained from the Inter BioScreen natural compound library (IBS), and 68 anticancer natural compounds that have been reported in the published literature.

All selected natural compounds were docked with the X-ray crystal structure of the selected protein by employing GLIDE (Grid-based Ligand Docking with Energetics) Maestro 9.6. InterBioScreen natural compounds docked with each selected protein molecule by using GLIDE high throughput virtual screening.

On the basis of Gscore, we select 20 compounds along with 68 anticancer compounds for GLIDE extra precision molecular docking. It was discovered in this study that the compound epigallocatechin gallate (EGCG) (Figure 34) yielded a magnificent Gscore with IGF1R (PDB; 1K3A) and VEGFIIR (PDB; 2OH4), and the protein-ligand interactions have been charted out.

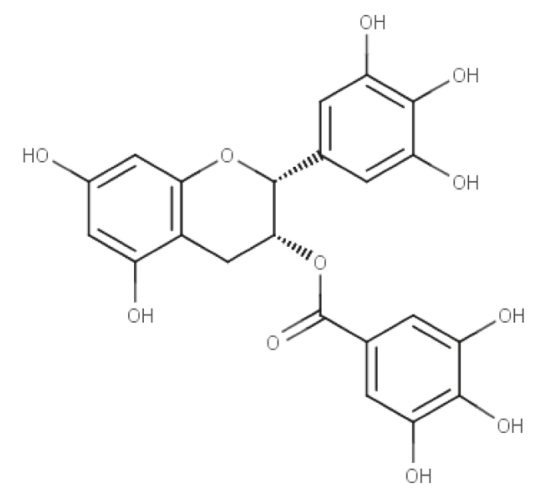

FIGURE 34 - Chemical structure of epigallocatechin gallate (EGCG).

In another study, Singh and Bast (2015b), utilizing the same workflow of screening for multitargeted compounds, performed multitargeted molecular docking of tyrosine kinase receptors (RTKs) against natural compounds with the aim of finding multiple potential target inhibitors of insulin, epidermal growth factor, and androgen receptor involved in the development of several types of cancer. The RTKs are trans-membrane receptors that regulate a number of cellular activities, including cell migration, adhesion, apoptosis, and cell proliferation. Overexpression or overactivity of RTKs has been reported in a diverse of cancers, including prostate, breast, lung, and ovarian cancers.

To investigate the effect of natural compounds on cancer cell growth and apoptosis by using in silico and in vitro, a dataset of 50000 ligands were used in this study obtained from the Inter BioScreen natural compound library (IBS), and 68 anticancer natural compounds that have been reported in the publish literature. In the present study, CID5281672 (myricetin) (Figure 35) showing a high Gscore for EGFR and IR as compared to their respective controls. Molecular docking results of EGFR (PDB, 1M17) and IR (PDB, 3ETA) against natural compounds revealed that myricetin had a better Gscore, -10.47 and $-9.92 \mathrm{Kcal} / \mathrm{mol}$, respectively.

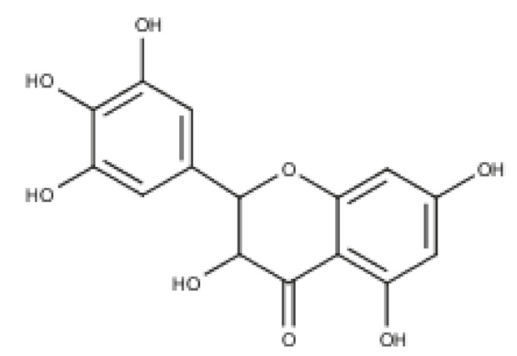

FIGURE 35 - Chemical structure of CID5281672 (myricetin).

Singh and Bast (2014) aimed to find a natural product that can be developed as a suitable PI3K signaling pathway inhibitor by using molecular docking studies. In this study, PI3K signaling components PI3K, PDK1, Akt, and $\mathrm{mTOR}$ were chosen and 51 natural compounds along with 17 reference compounds were selected as ligands with the aid of a PubMed published literature search. Ligands were docked to protein molecules by using Maestro 9.3 (Schrödinger Inc.).

Myricetin, quercetin, morin, luteolin, and emodin (Figure 36) had significantly better energy scores than previously reported PI3K pathway inhibitors. These compounds have the best docking free energy score against PDK1 and PI3K.

Chen and Chen (2010) carried out a study using cheminformatics tools for the design of dual inhibitors of heat shock protein 90 (HSP90) and human epidermal growth factor receptor 2 (HER2). HSP90 and HER2 are two key cancer markers actively involved in various signal pathways for the growth of cancer cells.

In this study, 48 compounds were used for the training and additionally 12 compounds were used for the validation. 
(a)<smiles>O=c1c(O)c(-c2cc(O)c(O)c(O)c2)oc2cc(O)cc(O)c12</smiles>

(b)<smiles>O=C1c2c(O)cc(O)cc2OC(c2ccc(O)c(O)c2)C1O</smiles>

(c)<smiles>O=C1c2c(O)cc(O)cc2OC(c2ccc(O)cc2O)C1O</smiles>

(d)<smiles>O=c1c(O)c(-c2ccc(O)c(O)c2)oc2cc(O)cc(O)c12</smiles>

(e)<smiles>Cc1cc(O)c2c(c1)C(=O)c1cc(O)cc(O)c1C2=O</smiles>

FIGURE 36 - Chemical structures of (a) myricetin, (b) quercetin, (c) morin, (d) luteolin, and (e) emodin.

The inhibitory activity of these compounds for HER2 were obtained indirectly from the study of Llauger (Llauger et al., 2005; He et al., 2006). Through comparative molecular field analysis (CoMFA), comparative analyses of molecular similarity indexes (CoMSIA), and pharmacophase analysis it was possible to generate predictive models of the inhibitory activity of this protein.

The results of the CoMFA model showed a highly predictive $\mathrm{r} 2$ value with 0.922 and 0.885 in HSP90 and HER2, respectively. In the CoMSIA model, the r2 values were 0.967 and 0.936 in HSP90 and HER2, respectively. The contour maps of both targets showed that there were similar regions of a bulky favored area. Based on these results, the key criteria for designing a dual-target inhibitor for HSP90 and HER2 should consider the steric disfavor region in HSP90 and the electronegative favor and the hydrogen bond donor favor regions in HER2.

Additionally, the Hypogen results for HER2 showed high cost differences at 59.13 and an $r$-value as 0.909 . At the $\mathrm{C} 2$ position of the benzene ring, the HER 2 model favored steric bulkier substitutes more than HSP90. The Hypogen results for HSP90 also showed reliable values in cost difference, 85.82, and $r$-value, 0.902. The first hypothesis maps of HER2 and HSP90 contained the same features: one hydrophobic feature, one hydrogen bond donor feature, and two hydrogen bond acceptor features.

Although both receptors had similar hypotheses, the orientation of the pharmacophore features was distinctly different, especially for the hydrogen bond acceptor feature. Comparison of HER 2 and HSP90 pharmacophores gave a RMSD of 2.002. These results suggest that the effective compounds should have similar structural features but can adapt different poses in HER2 and HSP90 active sites. Overall, we investigated the significances of QSAR models and pharmacophore features for designing the HER2/HSP90 dual-targeted inhibitors.

\section{CONCLUSIONS}

In this review we discussed the importance of multitarget compounds in the treatment of various diseases, which are highly effective when related to complex and multifactorial diseases. We verified during the course of our researches that the use of in silico methods in drug design emerges as an advantageous process, since this investigation presupposes better results with lower expenses, as well as performs screening for several receptors that can interact with the drug, allowing the validation of a greater number of activities that can be tested a posteriori. The multitarget therapies presented here for each disease qualify the chemical structure in the discovery of new targets, thus favoring the increase of activity against diseases.

\section{REFERENCES}

Abdolmaleki A, Ghasemi JB, Ghasemi F. Computer aided drug design for multi-target drug design: SAR/QSAR, molecular docking and pharmacophore methods. Curr Drug Targets. 2017;18(5):556-575.

Aguilera E, Varela J, Birriel E, Serna E, Torres S, Yaluff G, et al. Potent and selective inhibitors of Trypanosoma cruzi triosephosphate isomerase with concomitant inhibition of cruzipain: inhibition of parasite growth through multitarget activity. Chem Med Chem. 2016;11(12):1328-38. 
Arboleda M, Jaramillo L, Ortiz D, Díaz A. Leishmaniasis cutánea y herpes zoster multidermatómico. Rev Chil Infecto. 2013;30(6):680-682.

Arshad OA, Datta A. Towards targeted combinatorial therapy design for the treatment of castration-resistant prostate cancer. BMC Bioinformatics. 2017;18(Suppl 4):134.

Ban F, Dalal K, Li H, LeBlanc E, Rennie PS, Cherkasov A. Best practices of computer-aided drug discovery: lessons learned from the development of a preclinical candidate for prostate cancer with a new mechanism of action. J Chem Inf Model. 2017;57(5):1018-1028.

Bawa P, Pradeep P, Kumar P, Choonara YE, Modi G, Pillay V. Multi-target therapeutics for neuropsychiatric and neurodegenerative disorders. Drug Discov Today. 2016;21(12):1886-1914.

Belluti F, Uliassi E, Veronesi G, Bergamini C, Kaiser M, Brun R, et al. Toward the development of dual-targeted glyceraldehyde3-phosphate dehydrogenase/trypanothione reductase inhibitors against Trypanosoma brucei and Trypanosoma cruzi. Chem Med Chem. 2014;9(2):371-82.

Bernal FA, Coy-Barrera E. In-silico analyses of sesquiterpenerelated compounds on selected Leishmania enzyme-based targets. Molecule. 2014;19(5):5550-5569.

Bishop T, Sham P. Analysis of Multifactorial Diseases. New York: Academic Press; 2000; 1-320.

Borowski P, Lang M, Haag A, Schmitz H, Choe J, Chen HM, et al. Characterization of imidazo [4, 5-d] pyridazine nucleosides as modulators of unwinding reaction mediated by West Nile virus nucleoside triphosphatase/helicase: evidence for activity on the level of substrate and/or enzyme. Antim Ag Chemoth. 2002;46(5):1231-9.

Chang KH, Yan MD, Yao CJ, Lin PC, Lai GM. Honokiolinduced apoptosis and autophagy in glioblastoma multiforme cells. Oncol Lett. 2013;6(5):1435-38.

Chen C, Chen C. Insights into designing the dual-targeted HER2/ HSP90 inhibitors. J Molecular Graph Model. 2010;29(1):21-31.

Christopher M, Overall, KO. Validating matrix metalloproteinases as drug targets and anti-targets for cancer therapy. Nat Rev Cancer. 2006;6:227-39.
Cui HS, Huang LS, Sok DE, Shin J, Kwon BM, Youn UJ, et al. Protective action of honokiol, administered orally, against oxidative stress in brain of mice challenged with NMDA. Phytomed. 2007;14(10):696-700.

De Souza W. Doenças negligenciadas. Rio de Janeiro: Academia Brasileira de Ciências; 2010.

Decker M. Design of hybrid molecules for drug development. Amsterdam: Elsevier; 2017.

Dileep KV, Remya C, Tintu I, Sadasivan C. Designing of multitarget-directed ligands against the enzymes associated with neuroinflammation: an in silico approach. Front Life Sci. 2013;7(3-4):174-85.

Drugs for Neglected Diseases Initiative. What is Chagas Disease? Disponível em: https://www.dndi.org/diseasesprojects/chagas/. Acesso em: 28 de fev 2018. (a).

Drugs for Neglected Diseases initiative (DNDi). What is Leishmaniasis? Disponível em: https://www.dndi.org/diseasesprojects/leishmaniasis/. Acesso em: 28 de fev 2018. (b).

Edache EI, Hambali HU, Arthur DE, Oluwaseye A, Chinweuba OC. In-silico discovery and simulated selection of multi-target Anti-HIV-1 inhibitors. Int Res J Pure Appl Chem. 2016,11(1):115 .

Edache EI, Uzairu A, Abechi SE. Multivariate QSAR study of indole $\beta$ - Diketo Acid, diketo acid and carboxamide derivatives as potent anti-HIV agents. Int J Innov Res Dev. 2015;4(9):374390 .

Espinoza-Fonseca LM. Targeting MDM2 by the small molecule RITA: towards the development of new multi-target drugs against cancer. Theor Biol Med Model. 2005;2(1):38.

Flinn IW, O’Brien S, Kahl B, Patel M, Oki Y, Foss FF, et al. Duvelisib, a novel oral dual inhibitor of PI3K- $\delta, \gamma$, is clinically active in advanced hematologic malignancies. Blood. 2018;131(8):877-887.

Friesner RA, Banks JL, Murphy RB, Halgren TA, Klicic JJ, Mainz DT, et al. Glide: a new approach for rapid, accurate docking and scoring. 1. Method and assessment of docking accuracy. J Med Chem. 2004;47(7):1739-1749. 
Friesner RA, Murphy RB, Repasky MP, Frye LL, Greenwood JR, Halgren TA, et al. Extra precision glide: docking and scoring incorporating a model of hydrophobic enclosure for proteinligand complexes. J Med Chem. 2006;49(21):6177-6196.

Gao L, Fang JS, Bai XY, Zhou D, Wang YT, Liu AL, et al. In silico target fishing for the potential targets and molecular mechanisms of baicalein as an antiparkinsonian agent: discovery of the protective effects on NMDA receptor-mediated neurotoxicity. Chem Bio Drug Design. 2013;81(6):675-87.

García I, Fall Y, Gómez G, González-Díaz H. First computational chemistry multitarget model for anti-Alzheimer, anti-parasitic, antifungi, and anti-bacterial activity of GSK-3 inhibitors in vitro, in vivo, and in different cellular lines. Mol Divers. 2011;15(2):561-7.

Ge QF, Hu X, Ma ZQ, Liu JR, Zhang WP, Chen Z, et al. Baicalin attenuates oxygen-glucose deprivation-induced injury via inhibiting NMDA receptor-mediated 5-lipoxygenase activation in rat cortical neurons. Pharmacol Res. 2007;55(2):148-57.

Gentile C, Martorana A, Lauria A, Bonsignore R. Kinase inhibitors in multitargeted cancer therapy. Curr Med Chem. 2017;24(16):1671-1686.

Gill AL, Verdonk M, Boyle RG, Taylor R. A comparison of physicochemical property profiles of marketed oral drugs and orally bioavailable anti-cancer protein kinase inhibitors in clinical development. Curr Top Med Chem. 2007;7(14):140822.

Gordon RK, Nigam SV, Weitz JA, Dave JR, Doctor BP, Ved HS. The NMDA receptor ion channel: a site for binding of Huperzine A. J Appl Toxicol. 2001;21(Suppl 1):47-51.

Halgren TA, Murphy RB, Friesner RA, Beard HS, Frye LL, Pollard WT, et al. Glide: A new approach for rapid, accurate docking and scoring. 2. Enrichment factors in database screening. J Med Chem. 2004;47(7):1750-1759.

He H, Zatorska D, Kim J, Aguirre J, Llauger L, She Y, et al. Identification of potent water soluble purine-scaffold inhibitors of the heat shock protein 90. J Med Chem. 2006;49(1):381-390.

Hui Al, Chen Y, Zhu SJ, Gan CS, Pan J, Zhou A. Design and synthesis of tacrine-phenothiazine hybrids as multitarget drugs for Alzheimer's disease. Med Chem Res. 2014;23:3546-57.
Jayaraman P, Sakharkar KR, Lim CS, Siddigi MI, Dhillon SK e Sakharkar, MK. Novos conjugados fitoquímico-antibióticos como inibidores multitarget de Pseudomononas aeruginosa GyrB / ParE e DHFR. Drug Des Devel Ther. 2013;7:449-475.

Johnston MI, Hoth DF. Present status and future prospects for HIV therapies. Science. 1993;260(5112):1286-1293.

Jorissen RN, Reddy GS, Ali A, Altman MD, Chellappan S, Anjum SG, et al. Additivity in the analysis and design of HIV protease inhibitors. J Med Chem. 2009;52(3):737-54.

Jung CG, Horike H, Cha BY, Uhm KO, Yamauchi R, Yamaguchi T, et al. Honokiol increases ABCA1 expression level by activating retinoid X receptor beta. Biol Pharm Bull. 2010;33(7):1105-11

Kaushik G, Ramalingam S, Subramaniam D, Rangarajan P, Protti P, Rammamoorthy $\mathrm{P}$, et al. Honokiol induces cytotoxic and cytostatic effects in malignant melanoma cancer cells. Am J Surg. 2012;204(6):868-73.

Keith CT, Borisy AA, Stockwell BR. Multicomponent therapeutics for networked systems. Nat Rev Drug Discov. 2005;4(1):71-8.

Kotani H, Tanabe H, Mizukami H, Amagaya S, Inoue M. A naturally occurring rexinoid, honokiol, can serve as a regulator of various retinoid X receptor heterodimers. Biol Pharm Bull. 2012;35(1):1-9.

Konecny GE, Pegram MD, Venkatesan N, Finn R, Yang G, Rahmeh M, et al. Activity of the dual kinase inhibitor lapatinib (GW572016) against HER-2-overexpressing and trastuzumabtreated breast cancer cells. Cancer Res. 2006;66(3):1630-1639.

Krug M, Hilgeroth A. Recent advances in the development of multi-kinase inhibitors. Mini Rev Med Chem. 2008;8(13):131227.

Kumar A, Jain S, Parle M, Jain N, Kumar P. 3-Aryl-1-phenyl$1 \mathrm{H}$-pyrazole derivatives as new multitarget directed ligands for the treatment of Alzheimer's disease, with acetylcholinesterase and monoamine oxidase inhibitory properties. EXCLI J. 2013;12:1030-42.

Lansbury PT. Back to the future: the "old-fashioned" way to new medications for neurodegeneration. Nat Rev Neurosci. 2004;5(Suppl):51-57. 
Lavecchia A, Di Giovanni C. Virtual screening strategies in drug discovery: a critical review. Curr Med Chem. 2013;20(23):283960 .

Li J, Wu HM, Zhou RL, Liu GJ, Dong BR. Huperzine A for Alzheimers disease. Cochrane Database Syst Rev. 2008;(2):CD005592.

Li Y, Tan C, Gao C, Zhang C, Luan X, Chen X, et al. Discovery of benzimidazole derivatives as novel multi-target EGFR, VEGFR-2 and PDGFR kinase inhibitors. Bioorg Med Chem. 2011;19(15):4529-4535.

Li YH, Wang PP, Li XX, Yu CY, Yang H, Zhou J, et al. The human kinome targeted by FDA approved multi-target drugs and combination products: a comparative study from the drug-target interaction network perspective. PLoS One. 2016;11(11):e0165737.

Lin S, Li Y, Zheng Y, Luo L, Sun Q, Ge Z, et al. Design, synthesis and biological evaluation of quinazoline-phosphoramidate mustard conjugates as anticancer drugs. Eur J Med Chem. 2017;127:442-458

Liu Qi, Che D, Huang Qi, Cao Z, Zhu R. Multi-target QSAR study in the analysis and design of HIV-1 inhibitors. Chin J Chem. 2010;28:1587-1592.

Llauger L, He H, Kim, J, Aguirre J, Rosen N, Peters U, et al. Evaluation of 8-arylsulfanyl, 8-arylsulfoxyl, and 8-arylsulfonyl adenine derivatives as inhibitors of the heat shock protein $90 . \mathrm{J}$ Med Chem. 2005;48(8):2892-2905.

Lorenzo VP, Lúcio ASSC, Scotti L, Tavares JF, Barbosa Filho JM, Lima TKS, et al. Structure-and ligand-based approaches to evaluate aporphynic alkaloids from annonaceae as multitarget agent against Leishmania donovani. Curr Pharm Design. 2016;22(34):5196-5203.

Loría-Cervera EN, Andrade-Narváez FJ. Animal models for the study of leishmaniasis immunology. Rev Inst Med Trop. 2014;56(1):1-11.

Luan X, Gao C, Zhang N, Chen Y, Sun Q, Tan C, et al. Exploration of acridine scaffold as a potentially interesting scaffold for discovering novel multi-target VEGFR-2 and Src kinase inhibitors. Bioorg Med Chem. 2011;19(11):3312-3319.
Luco JM, Ferretti FH. QSAR based on multiple linear regression and PLS methods for the anti-HIV activity of a large group of HEPT derivatives. J Chem Inform Comp Sci. 1997;37(2):392401 .

Ma XH, Shi Z, Tan C, Jiang Y, Go ML, Low BC, Chen YZ. InSilico approaches to multi-target drug discovery. Pharm Res. 2010;27(5):739-749.

Marzaro G, Chilin A, Guiotto A, Uriarte E, Brun P, Castagliuolo I, et al. Using the TOPS-MODE approach to fit multi-target QSAR models for tyrosine kinases inhibitors. Eur J Med Chem. 2011;46(6):2185-2192.

Mayank, Jaitak V. Molecular docking study of natural alkaloids as multi-targeted hedgehog pathway inhibitors in cancer stem cell therapy. Computat Biol Chem. 2016;62:145-154.

Morphy JR. Chapter 10 the challenges of multi-target lead optimization. In: Morphy JR, Harris CJ (editors). Designing Multi-Target Drugs. London: The Royal Society of Chemistry; 2012; 141-154.

Morphy R, Rankovic Z. Designed multiple ligands. An emerging drug discovery paradigm. J Med Chem. 2005;48(21):6523-6543.

Morphy R, Rankovic Z. Fragments, network biology and designing multiple ligands. Drug Discov Today. 2007;12(34):156-60.

Muller R. Crosstalk of oncogenic and prostanoid signaling pathways. J Cancer Res Clin Oncol. 2004;130:429-44.

Mustafa MS, Rastogi V, Jain S, Gupta V. Discovery of fifth serotype of dengue virus (DENV-5): A new public health dilemma in dengue control. Med J Arm Forc India. 2015;71(1):67-70.

Ning CQ, Lu C, Hu L, Bi Y, Yao L, He YJ, et al. Macrocyclic compounds as anti-cancer agents: Design and synthesis of multiacting inhibitors against HDAC, FLT3 and JAK2. Eur J Med Chem. 2015;95:104-115.

Paul N, Carabet LA, Lallous N, Yamazaki T, Gleave ME, Rennie PS, et al. Cheminformatics modeling of adverse drug responses by clinically relevant mutants of human androgen receptor. J Chem Inf Model. 2016;56(12):2507-2516. 
Pieretti S, Haanstra JR, Mazet M, Perozzo R, Bergamini C, Prati F, et al. Naphthoquinone derivatives exert their antitrypanosomal activity via a multi-target mechanism. PLOS Negl Trop Dis. 2013;7(1):2012-24.

Pilpel Y, Sudarsanam P, Church GM. Identifying regulatory networks by combinatorial analysis of promoter elements. Nat Genet. 2001;29(2):153-9.

Portela MPM, Villamil SHF, Perissinotti LJ, Stoppani AO. Redox cycling of o-naphthoquinones in trypanosomatids. Superoxide and hydrogen peroxide production. Biochem Pharmacol. 1996;52(12):1875-82.

Prati F, Simone A, Bisignano P, Armirotti A, Summa M, Pizzirani D, et al. Multitarget Drug Discovery for Alzheimer's Disease: Triazinones as BACE- 1 and GSK-3 $\beta$ Inhibitors. Ang Chem Intern Ed. 2015;54(5):1578-82.

Qamar MT, Mumtaz A, Naseem R, Ali A, Fatima T, Jabbar T, et al. Molecular docking based screening of plant flavonoids as dengue NS1 inhibitors. Bioinfo. 2014;10(7):460-5.

Ramsay RR, Popovic-Nikolic MR, Nikolic K, Uliassi E, Bolognesi ML. A perspective on multi-target drug discovery and design for complex diseases. Clin Transl Med. 2018;7(1):3.

Reithinger R, Dujardin JC, Louzir H, Pirmez C, Alexander B, Brooker S. Cutaneous leishmaniasis. Lancet Infect Dis. 2007;7(9):581-596.

Saeed M, Kuete V, Kadioglu O, Börtzler J, Khalid H, Greten, HJ, et al. Cytotoxicity of the bisphenolic honokiol from Magnolia officinalis against multiple drug-resistant tumor cells as determined by pharmacogenomics and molecular docking. Phytomed. 2014;21(12):1525-33.

Sankarasubramanian J, Pavithra KB, Kavitha B. Identification of potent inhibitor for RNA dependent RNA polymerase (RDRP) of dengue virus serotype-3: a molecular docking study. J Appl Bioinform Comput Biol. 2015;4:1-6.

Schmidt D, Bernat V, Brox R, Tschammer N, Kolb P. Identifying modulators of $\mathrm{CXC}$ receptors 3 and 4 with tailored selectivity using multi-target docking. ACS Chem Biol. 2015;10(3):715724.

Senthilvel P, Lavanya P, Kumar KM, Swetha R, Anitha P, Bag S, et al. Flavonoid from Carica papaya inhibits NS2BNS3 protease and prevents Dengue 2 viral assembly. Bioinfo. 2013;9(18):889-95.
Sergina NV, Rausch M, Wang D, Blair J, Hann B, Shokat KM, et al. Escape from HER-family tyrosine kinase inhibitor therapy by the kinase-inactive HER3. Nature. 2007;445(7126):437-41.

Singh P, Bast F. Multitargeted molecular docking study of plantderived natural products on phosphoinositide-3 kinase pathway components. Med Chem Res. 2014;23(4):1690-1700.

Singh P, Bast F. Screening and biological evaluation of myricetin as a multiple target inhibitor insulin, epidermal growth factor, and androgen receptor; in silico and in vitro. Investigational New Drugs. 2015a;33(3):575-593.

Singh P, Bast F. Screening of multi-targeted natural compounds for receptor tyrosine kinases inhibitors and biological evaluation on cancer cell lines, in silico and in vitro. Med Oncol. 2015b;32(9):233.

Sousa LRF, Wu H, Nebo L, Fernandes JB, Silva MFGF, Kiefer $\mathrm{W}$, et al. Flavonoids as noncompetitive inhibitors of dengue virus NS2B-NS3 protease: Inhibition kinetics and docking studies. Bioorg Med Chem. 2015;23(3):466-70.

Speck-Planche A, Kleandrova V, Luan F, Cordeiro NDS. Multitarget inhibitors for proteins associated with Alzheimer: in silico discovery using fragment-based descriptors. Curr Alzheimer Res. 2013;10(2):117-24.

Speck-Planche A, Kleandrova VV, Luanac F, Cordeiro MNDS. A ligand-based approach for the in silico discovery of multitarget inhibitors for proteins associated with HIV infection. Mol BioSyst. 2012;8(8):2188-2196.

Speck-Planche A, Kleandrova VV, Luanac F, Cordeiro MNDS. Multi-target drug discovery in anti-cancer therapy: Fragmentbased approach toward the design of potent and versatile antiprostate cancer agentes. Bioorg Med Chem. 2011;19:6239-6244.

Steinbrecher TB, Dahlgren M, Cappel D, Lin T, Wang L, Krilov $\mathrm{G}$, et al. Accurate binding free energy predictions in fragment optimization. J Chem Inf Model. 2015;55(11):2411-2420.

Stolp ZD, Smurthwaite CA, Connor R, Williams W, Dharmawan A, Diaballah H, et al. A multiplexed cell based assay for the identification of modulators of pre-membrane processing as a target against dengue virus. J Biomol Screen. 2015;20(5):616-26.

Sundar S, Rai M. Advances in the treatment of leishmaniasis. Curr Opin Infect Dis. 2002;15(6):593-598. 
Szelag M, Czerwoniec A, Wesoly J, Bluyssen HAR. Identification of STAT1 and STAT3 specific inhibitors using comparative virtual screening and docking validation. Plos One. 2015:10(2):e0116688.

Tambunan USF, Apriyanti N, Parikesit AA, Chua W, Wuryani K. Computational design of disulfide cyclic peptide as potential inhibitor of complex NS2B-NS3 dengue virus protease. Afric J Biotech. 2011;10(57):12281-90.

Trossini GH, Maltarollo VG, Schmidt TJ. Hologram QSAR studies of antiprotozoal activities of sesquiterpene lactones. Molecules. 2014;19(7):10546-10562.

Vincetti P, Caporuscio F, Kaptein S, Gioiello A, Mancino V, Suzuki Y, et al. Discovery of multitarget antivirals acting on both the Dengue virus NS5-NS3 interaction and the host Src/ Fyn kinases. J Med Chem. 2015;58(12):4964-75.

Vogelstein B, Lane D, Levine AJ. Surfing the p53 network. Nature. 2000;408(6810): 307-310.

Wang R, Yan H, Tang XC. Progress in studies of huperzine A, a natural cholinesterase inhibitor from Chinese herbal medicine. Acta Pharmacol Sin. 2006;27(1):1-26.

Wang ZF, Wang J, Zhang HY, Tang XC. Huperzine A exhibits anti-inflammatory and neuroprotective effects in a rat model of transient focal cerebral ischemia. J Neurochem. 2008;106(4):1594-1603.

Wavefunction, Inc. Spartan'14, version 1.1.2, Irvine, California, USA; 2013.

Watts C. Neglected tropical diseases: A DFID perspective. PLoS Negl Trop Dis. 2017;11(4):e0005492.

World Health Organization (WHO). Chagas disease (American trypanosomiasis), 2018a. Disponível em: http://www.who.int/ chagas/disease/treatment/en/. Acesso em: 28 fev 2018.

World Health Organization (WHO). Dengue Control, 2018b. Disponível em: http://www.who.int/denguecontrol/ epidemiology/en/. Acesso em: 26 fev 2018.

World Health Organization (WHO). Epidemiological situation, 2018c. Disponível em: http://www.who.int/leishmaniasis/ burden/en/. Acesso em: 28 fev 2018.
World Health Organization (WHO). Neglected tropical diseases, 2018d. Disponível em: http://www.who.int/neglected_diseases/ resources/9789241564090/en/. Acesso em: 26 fev 2018.

World Health Organization (WHO). Working to overcome the global impact of neglected tropical diseases: First WHO report on Neglected Tropical Diseases, 2010. Disponível em: http:// www.who.int/neglected_diseases/resources/9789241564090/ en/. Acesso em: 26 fev 2018.

Xu M, Chen X, Gu Y, Peng T, Yang D, Chang RC. Baicalin can scavenge peroxynitrite and ameliorate endogenous peroxynitrite-mediated neurotoxicity in cerebral ischemiareperfusion injury. J Ethnopharmacol. 2013;150(1):116-24.

Yan J, Sun L, Wu G, Yi P, Yang F, Zhou L, et al. Rational design and synthesis of highly potent anti-acetylcholinesterase activity huperzine A derivatives. Bioorg Med Chem. 2009;17(19):693741.

Yap CW. PaDEL-descriptor: An open source software to calculate molecular descriptors and fingerprints. JComp Chem. 2011;32(7):1466-1474.

Yildirim MA, Goh KI, Cusick ME, Barabasi AL, Vidal M. Drugtarget network. Nat Biotechnol. 2007;25(10):1119-26.

Yousuf Z, Iman K, Iftikhar N, Mirza UM. Structure-based virtual screening and molecular docking for the identification of potential multi-targeted inhibitors against breast cancer. Breast Cancer: Targets Ther. 2017;9:447-459.

Yuan Z, Chen S, Sun Q, Wang N, Li D, Miao S, et al. Olaparib hydroxamic acid derivatives as dual PARP and HDAC inhibitors for cancer therapy. Bioorg Med Chem. 2017;25(15):4100-4109.

Zhang P, Liu X, Zhu Y, Chen S, Zhou D, Wang Y. Honokiol inhibits the inflammatory reaction during cerebral ischemia reperfusion by suppressing NF- $\kappa \mathrm{B}$ activation and cytokine production of glial cells. Neurosci Lett. 2013;534:123-127.

Zhang WT, Jiang FC, Liu D, Du G. Pharmacopore hypothesis generation of BACE-1 inhibitors and pharmacophore-driven identification of potent multi-target neuroprotective agents. Med Chem Res. 2012;21(11):3656-3668. 
Drug discovery and computational strategies in the multitarget drugs era

Zhang Z, Zheng M, Du L, Shen J, Luo X, Zhu W, Jiang H. Towards discovering dual functional inhibitors against both wild type and K103N mutant HIV-1 reverse transcriptases: molecular docking and QSAR studies on 4,1-benzoxazepinone analogues. J Comput Aided Mol Des. 2006;20(5):281-293.

Zheng CY, Zhang HY, Tang XC. Huperzine A attenuates mitochondrial dysfunction after middle cerebral artery occlusion

in rats. J Neurosci Res. 2008;86(11):2432-40.
Zhou Y, Shan S, Li Z, Xin L, Pan D, Yang Q, et al. CS2164, a novel multi-target inhibitor against tumor angiogenesis, mitosis and chronic inflammation with anti-tumor potency. Cancer Sci. 2017;108(3):469-477. 